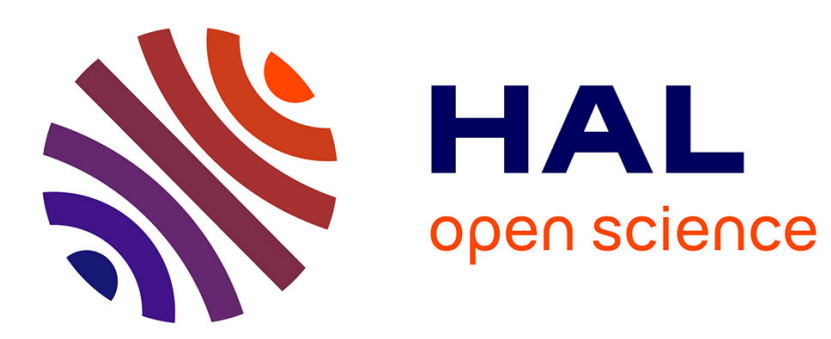

\title{
Global shortwave energy budget at the earth's surface from ERBE observations
}

\author{
François-Marie Breon, Robert Frouin, Catherine Gautier
}

\section{To cite this version:}

François-Marie Breon, Robert Frouin, Catherine Gautier. Global shortwave energy budget at the earth's surface from ERBE observations. Journal of Climate, 1994, 7 (2), pp.309-324. 10.1175/15200442(1994)0072.0.CO;2 . hal-03334809

\section{HAL Id: hal-03334809 \\ https://hal.science/hal-03334809}

Submitted on 5 Sep 2021

HAL is a multi-disciplinary open access archive for the deposit and dissemination of scientific research documents, whether they are published or not. The documents may come from teaching and research institutions in France or abroad, or from public or private research centers.
L'archive ouverte pluridisciplinaire HAL, est destinée au dépôt et à la diffusion de documents scientifiques de niveau recherche, publiés ou non, émanant des établissements d'enseignement et de recherche français ou étrangers, des laboratoires publics ou privés. 


\title{
Global Shortwave Energy Budget at the Earth's Surface from ERBE Observations
}

\author{
FRANÇOIS-MARIE BREON ${ }^{\dagger}$ AND ROBERT FROUIN \\ California Space Institute, Scripps Institution of Oceanography, La Jolla, California \\ CATHERINe GAUTIER \\ Earth-Space Science Group, University of California, Santa Barbara, Santa Barbara, California
}

(Manuscript received 2 December 1991, in final form 9 September 1993)

\begin{abstract}
A method is proposed to compute the net solar (shortwave) irradiance at the earth's surface from Earth Radiation Budget Experiment (ERBE) data in the $\mathrm{S} 4$ format. The $\mathrm{S} 4$ data are monthly averaged broadband planetary albedo collected at selected times during the day. Net surface shortwave irradiance is obtained from the shortwave irradiance incident at the top of the atmosphere (known) by subtracting both the shortwave energy flux reflected by the earth-atmosphere system (measured) and the energy flux absorbed by the atmosphere (modeled). Precalculated atmospheric- and surface-dependent functions that characterize scattering and absorption in the atmosphere are used, which makes the method easily applicable and computationally efficient. Four surface types are distinguished, namely, ocean, vegetation, desert, and snow/ice. Over the tropical Pacific Ocean, the estimates based on ERBE data compare well with those obtained from International Satellite Cloud Climatology Project (ISCCP) B3 data. For the 9 months analyzed the linear correlation coefficient and the standard difference between the two datasets are 0.95 and $14 \mathrm{~W} \mathrm{~m}^{-2}$ (about $6 \%$ of the average shortwave irradiance), respectively, and the bias is $15 \mathrm{~W} \mathrm{~m}^{-2}$ (higher ERBE values). The bias, a strong function of ISCCP satellite viewing zenith angle, is mostly in the ISCCP-based estimates. Over snow/ice, vegetation, and desert no comparison is made with other satellite-based estimates, but theoretical calculations using the discrete ordinate method suggest that over highly reflective surfaces (snow/ice, desert) the model, which accounts crudely for multiple reflection between the surface and clouds, may substantially overestimate the absorbed solar energy flux at the surface, especially when clouds are optically thick. The monthly surface shortwave irradiance fields produced for 1986 exhibit the main features characteristic of the earth's climate. As found in other studies, our values are generally higher than Esbensen and Kushnir's by as much as $80 \mathrm{~W} \mathrm{~m}^{-2}$ in the tropical oceans. A cloud parameter, defined as the difference between clear-sky and actual irradiances normalized to top-of-atmosphere clear-sky irradiance, is also examined. This parameter, minimally affected by sun zenith angle, is higher in the midlatitude regions of storm tracks than in the intertropical convergence zone (ITCZ), suggesting that, on average, the higher cloud coverage in midlatitudes is more effective at reducing surface shortwave irradiance than opaque, convective, yet sparser clouds in the ITCZ. Surface albedo estimates are realistic, generally not exceeding 0.06 in the ocean, as high as 0.9 in polar regions, and reaching 0.5 in the Sahara and Arabian deserts.
\end{abstract}

\section{Introduction}

The solar radiation absorbed by the earth's surface is a major component of the surface heat budget. Knowledge of its magnitude, including spatial and temporal variability, is important for climate studies. Over the oceans, net surface solar (or shortwave) irradiance is required to understand the role of radiation in ocean-atmosphere interactions, to estimate merid-

\footnotetext{
${ }^{\dagger}$ Permanent affiliation: Laboratoire de Modélisation du Climat et de l'Environnement, CEA/DSM, Gif sur Yvette, France.

Corresponding author address: Dr. François-Marie Bréon, Laboratoire de Modélisation du Climat et de l'Environnement, CEA/DSM, 91191 Gif sur Yvette, France.
}

ional heat transport, and to validate coupled oceanatmosphere models. Over land, shortwave radiation absorbed by the surface, which governs the turbulent fluxes of latent and sensible heat, is required to investigate surface-atmosphere interactions. Monitoring surface shortwave irradiance is also useful in other research areas, such as primary productivity and global carbon cycling. A comprehensive description of more specific needs can be found, for instance, in Suttles and Ohrings (1986) and Sellers et al. (1990).

Many methods have been proposed to estimate surface shortwave irradiance from satellite narrowband radiance measurements (e.g., Tarpley 1979; Pinker and Ewing 1985; Gautier et al. 1980; Möser and Raschke 1984; Dedieu et al. 1987; Darnell et al. 1988). These methods make use of visible and near-infrared observations from sensors aboard geostationary satellites or 
polar orbiters. These observations, however, are not sensitive to all the wavelengths of the solar spectrum, and transforming the top-of-atmosphere (TOA) data into albedo averaged over the entire solar spectrum is not without uncertainties (e.g., Ramanathan 1986; Cess and Vulis 1989).

More recently, Frouin and Chertock (1992) described a method based on earth radiation budget (ERB) broadband planetary albedo measurements. Since they used ERB wide-field-of-view sensor data, the major drawback of their method is a spatial resolution not better than $1000 \mathrm{~km}$, which is not sufficient to observe some climatologically important features such as the intertropical convergence zone (ITCZ).

The Earth Radiation Budget Experiment (ERBE) (Barkstrom 1984), on the other hand, offers the opportunity, at least in principle, to estimate the surface shortwave radiation budget with an accuracy better than that previously attained because 1) it provides broadband measurements, and 2) it gives information on the TOA reflectance's diurnal cycle. Moreover, unlike the geostationary satellite data ordinarily used in radiation budget studies, the ERBE data covers the entire earth's surface, thus avoiding intercalibration uncertainties.

Incoming solar radiation at the top of the atmosphere is either reflected back to space (by the clear atmosphere, clouds, or the surface), absorbed by the clear atmosphere and clouds, or absorbed by the surface. The difference between TOA and surface shortwave radiation budgets is therefore equal to the amount of radiation absorbed by the atmosphere (gases, aerosols, and clouds). Clear-sky absorption represents about $15 \%$ of the incoming TOA flux. Its variability is small, depending mostly on water vapor, ozone, and aerosol contents, as well as the sun zenith angle. Cloud absorption, similarly, is a small fraction of cloud reflection. These facts have two main consequences: 1) there is a high correlation between TOA and surface shortwave radiation budgets, as mentioned by Ramanathan (1986) and others; and 2) surface absorption can be obtained from the TOA shortwave radiation budget by applying a relatively constant correction. Because atmospheric absorption variability is an order of magnitude smaller than surface absorption variability, a fairly high accuracy on the net surface flux can be achieved, even with large uncertainties in the parameters governing atmospheric absorption.

Let SURF denote the net shortwave flux at the surface, TOP the net shortwave flux at the top of the atmosphere, and ABSO the shortwave flux absorbed by the atmosphere. Ramanathan's (1986) simulations show that the flux ratio SURF/TOP is almost constant on a monthly time scale, regardless of the geographical region, and equal to about 0.8 . We can write:

$$
\frac{\text { SURF }}{\text { TOP }}=1-C
$$

with $C=0.2$. After some manipulation, we obtain:

$$
\frac{\mathrm{ABSO}}{F_{\mathrm{TOA}}^{\mathrm{H}}}=C\left(1-A_{\mathrm{TOA}}\right)
$$

where $F_{\mathrm{TOA}}^{\Downarrow}$ is the TOA incoming shortwave irradiance, and $A_{\text {TOA }}$ the TOA albedo.

Thus, the normalized shortwave flux absorbed by the atmosphere (including clouds) should decrease linearly as the TOA albedo increases. Its maximum value, on a monthly time scale, is close to $20 \%$. Two distinct effects may explain the decrease with increasing TOA albedo of the normalized shortwave flux absorbed by the atmosphere. First, clouds increase the TOA albedo, reducing the optical path through the atmosphere and, therefore, absorption. The second effect is more incidental: clear-sky planetary albedo increases poleward due to surface conditions and solar zenith angle effects, and clear-sky absorption decreases poleward because of reduced water vapor content. The relative importance of these effects is not known, and we cannot draw a conclusion about the linearity of the relationship between TOA albedo and normalized shortwave flux absorbed by the atmosphere from the above considerations, which are too qualitative.

Still, the relatively small and little-varying atmospheric absorption makes large the correlation between TOA and surface shortwave fluxes, implying that the surface flux may be retrieved with high accuracy from TOA albedo measurements (Ramanathan 1986; Cess and Vulis 1989). We cannot use the simple relation obtained from GCM simulations by Ramanathan (1986) since 1) a limited set of climatic regions was considered, 2) the GCM's radiative transfer scheme was too crude, and 3 ) the GCM was only run with perpetual-January boundary conditions.

Our approach is to seek a general yet highly parameterized relation between TOA and surface net shortwave fluxes that accounts for the major radiative processes occurring within the atmosphere and at the surface, including solar zenith angle effects. Since SURF $=\mathrm{TOP}-\mathrm{ABSO}$, and since TOP is measured, one may wonder why we did not simply model ABSO and perform the substraction. Modeling ABSO, however, is as complex as modeling SURF/TOP, because ABSO depends on atmospheric composition and surface type. In cloudy conditions, for instance, multiple reflections between the surface and clouds may affect ABSO differently depending on the spectral characteristics of the surface albedo. The case of clouds over varying surface types was not studied by Cess and Vulis (1989), who suggested that a priori knowledge of surface albedo may not be necessary, therefore simplifying the modeling of ABSO. Accounting for surface-type effects, however, requires at least a crude knowledge of the surface spectral albedo. All optical variables (albedos, transmittances) are weight averaged over the entire solar spectrum, and the weights are selected so that the SURF/ 
TOP ratio is accurately modeled in clear-sky conditions. The procedure is justified because we do not have any information about the cloudiness within the satellite pixels; yet it introduces uncertainties (discussed below) when clouds modify the spectral distribution of irradiance at the surface and in the atmosphere.

We first explain our method of estimating surface albedo and the shortwave budget from ERBE planetary albedo observations. This includes a description of the radiative transfer model used to compute the relationship between TOA and surface shortwave fluxes (section $2 \mathrm{a}$ ), a discussion of the various atmospheric functions used in the parameterizations (section $2 b$ ), and an evaluation of the method's advantages and drawbacks ( section 2c). Section 3 presents a comparison of ERBE-based estimates with those derived from International Satellite Cloud Climatology Project (ISCCP) B3 data. We then analyze global fields of surface albedo and shortwave flux obtained from 1986 ERBE data (section 4), and we finally summarize and conclude the study (section 5 ).

\section{Method}

\section{a. Model}

As indicated in the Introduction, we are interested in expressing simply the surface net shortwave flux as a function of the TOA net shortwave flux, the measured quantity. Let us model the surface/cloud/atmosphere system as the surface, and, above the surface, a homogeneous cloud layer topped with a clear atmosphere. In the formulation that follows, subscript "cld" refers to the cloud layer, "atm" to the clear atmosphere, "sur" to the surface, "sys" to the surface/cloud system, $A$ is albedo, $a$ is absorptance, $T$ is transmittance, and $F$ is shortwave flux.

The albedo of the surface/cloud system is equal to:

$$
A_{\text {sys }}=A_{\text {cld }}+\frac{A_{\text {sur }}\left(1-A_{\text {cld }}-a_{\mathrm{cld}}\right)^{2}}{1-A_{\text {sur }} A_{\text {cld }}}
$$

where the term $1-A_{\text {sur }} A_{\text {cld }}$ is introduced to account for multiple surface-cloud reflections. In Eq. (3), cloud albedo is assumed to be the same for upwelling and downwelling radiation. This is not strictly true as the upwelling and downwelling fluxes at the cloud boundaries may have a rather different angular and spectral distribution. Note, also, that Eq. (3) is only valid for monochromatic radiation, and its use with broadband quantities will require weight averaging over wavelength. In fact, throughout we reason with monochromatic quantities (or, equivalently, assume no spectral variations) to establish the expression for the shortwave irradiance absorbed by the surface; but in section $2 b$, we define the atmospheric and surface-dependent functions that appear in the equations (see below) so that spectral variations are accounted for properly.
The TOA surface-cloud-atmosphere albedo, similarly, is equal to:

$$
A_{\mathrm{TOA}}=A_{\mathrm{atm}}^{\Downarrow}+\frac{A_{\mathrm{sys}} T_{\mathrm{atm}}^{\mathrm{⿲} \hat{\mathrm{m}}}}{1-A_{\mathrm{sys}} A_{\mathrm{atm}}^{\Uparrow}}
$$

where the symbol $\Downarrow$ refers to downwelling radiation and the symbol $\Uparrow$ to upwelling radiation. Contrary to what is done for cloud albedo, we differentiate the atmospheric upwelling and downwelling atmospheric albedos because they are first-order terms and may take different values (see section 3). Moreover, we seek accurate modeling in clear-sky conditions ( see the Introduction). As in Eq. (3), the term $1-A_{\text {sys }} A_{\mathrm{atm}}^{\hat{\pi}}$ is introduced to account for multiple reflections between the atmosphere and the surface/cloud system.

Let us now express the shortwave irradiance absorbed by the surface, still in cloudy conditions. Accounting for multiple reflections between the various components of the surface/cloud/atmosphere system, we find:

$$
\begin{aligned}
F_{\text {sur }-\mathrm{abs}}= & F_{\mathrm{TOA}}\left(1-A_{\text {sur }}\right) \\
& \times \frac{\left(1-A_{\mathrm{cld}}-a_{\mathrm{cld}}\right)}{\left(1-A_{\mathrm{cld}} A_{\mathrm{sur}}\right)} \frac{T_{\mathrm{atm}}^{\Downarrow}}{\left(1-A_{\mathrm{sys}} A_{\mathrm{atm}}^{\Uparrow}\right)} .
\end{aligned}
$$

The first term in parentheses on the right-hand side of Eq. (5) is the surface absorptance, the first ratio accounts for cloud transmittance and multiple cloudsurface reflections, and the second ratio accounts for clear atmosphere transmittance and multiple cloudatmosphere reflections.

From Eqs. (3) and (4), we deduce the albedo at the top of the atmosphere in clear-sky conditions:

$$
A_{\mathrm{TOA}}^{\mathrm{cl}}=A_{\mathrm{atm}}^{\Downarrow}+\frac{A_{\mathrm{sur}} T_{\mathrm{atm}}^{\Downarrow \Uparrow}}{1-A_{\mathrm{sur}} A_{\mathrm{atm}}^{\Uparrow \Uparrow}}
$$

and, from Eq. (5), we deduce the shortwave irradiance absorbed by the surface in clear-sky conditions:

$$
F_{\text {sur-abs }}^{\mathrm{cir}}=F_{\mathrm{TOA}}\left(1-A_{\mathrm{sur}}\right) \frac{T_{\mathrm{atm}}^{\Downarrow}}{\left(1-A_{\mathrm{sur}} A_{\mathrm{atm}}^{\Uparrow}\right)} .
$$

Note that Eq. (6) gives access to the surface albedo from the clear-sky TOA albedo (satellite measurement) and the optical functions of the atmosphere, namely $A_{\mathrm{atm}}^{\Uparrow}, A_{\mathrm{atm}}^{\Downarrow}$, and $T_{\mathrm{atm}}^{\Downarrow \Uparrow}$.

In order to compute $F_{\text {sur }- \text { abs }}^{\mathrm{clr}}$ using Eq. (5), we need another relation that gives cloud absorptance as a function of cloud albedo. There have been many theoretical studies (e.g., Stephens et al. 1984) and experimental ones (e.g., Stephens et al. 1978; Foot 1988) that relate $A_{\text {cld }}$ and $a_{\text {cld }}$ to cloud liquid water content, the governing parameter. Even in the case of a planeparallel cloud, there has been no agreement between theoretical and measured values. Because of these discrepancies, cloud absorptance parameterizations are not satisfactory.

We therefore simply model cloud absorptance as 


$$
a_{\mathrm{cld}}=\alpha A_{\mathrm{cld}}
$$

where $\alpha$ depends on sun zenith angle. Values for $\alpha$ can be obtained from Stephens et al. (1984). Typically, $\alpha$ decreases from 0.15 to 0.05 as the sun goes from zenith to limb. This decrease reflects the fact that, as the sun zenith angle increases, more radiance is reflected back to space after a few interactions with cloud droplets, which implies smaller absorption (Bréon 1992). Our approximation is clearly crude, and it will be further discussed in section $2 \mathrm{~d}$.

\section{b. Atmospheric functions}

Computing solar irradiance absorbed by the surface using the model described above requires that several atmospheric and/or surface-dependent functions be specified, namely, the TOA (viewed from space) atmospheric albedo, $A_{\text {atm }}^{\Downarrow}$, the clear-sky downwelling atmospheric transmittance, $T_{\mathrm{atm}}^{\|}$, the clear-sky total (sun-to-surface and surface-to-TOA) atmospheric transmittance, $T_{\mathrm{atm}}^{\mathrm{y}}$, and the spherical albedo of the atmosphere, $A_{\mathrm{atm}}^{\mathrm{t}}$. These functions are obtained by spectral and angular integration of their bidirectional and spectrally dependent equivalents. They depend mostly on solar zenith angle, water vapor, ozone, and aerosol contents, as well as surface albedo (for some), and they are defined such that Eqs. (6) and (7), the clear-sky equations, are valid for broadband quantities. It would have been more accurate to define the functions such that Eqs. (4) and (5), the general case equations, are valid for broadband quantities, but this is not possible because we do not know the satellite pixel composition (i.e., fraction of clouds) and, therefore, the spectral dependence of the surface/cloud system.

The TOA atmospheric albedo, which represents photons that have been scattered back to space without surface reflection, is defined as:

$$
\begin{gathered}
A_{\mathrm{atm}}^{\Downarrow}(\theta)=\frac{1}{\pi}\left\{\int _ { 0 } ^ { \infty } d \lambda \int _ { 0 } ^ { \pi / 2 } d \theta ^ { \prime } \int _ { 0 } ^ { 2 \pi } d \phi ^ { \prime } \left[\rho_{a \lambda}\left(\theta, \theta^{\prime}, \phi\right)\right.\right. \\
\left.\left.\times t_{g \lambda}(\theta) t_{g \lambda}\left(\theta^{\prime}\right) E_{0 \lambda} \cos \theta^{\prime} \sin \theta^{\prime}\right] / \int_{0}^{\infty} d \lambda E_{0 \lambda}\right\}
\end{gathered}
$$

where $\rho_{a \lambda}$ is the TOA spectral path reflectance (Fig. 1a), $\lambda$ is the wavelength, $\theta$ is the sun zenith angle, $t_{g \lambda}$ is the spectral gaseous transmittance, and $E_{0 \lambda}$ is the extraterrestrial spectral solar irradiance. Most of the gaseous absorption occurs either at high altitude where molecules are rarefied (ozone absorption) or at wavelengths for which scattering is negligible (water vapor absorption). Gaseous absorption and scattering, therefore, can be decoupled in the computations, as in Tanré et al. (1990).

The clear-sky downwelling atmospheric transmittance, which characterizes the transparency of the clearsky atmosphere, is defined as

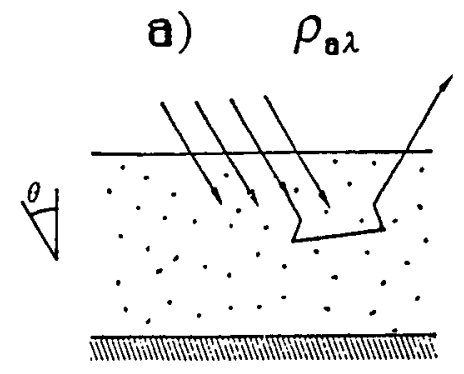

b) $\quad T_{d \lambda}$
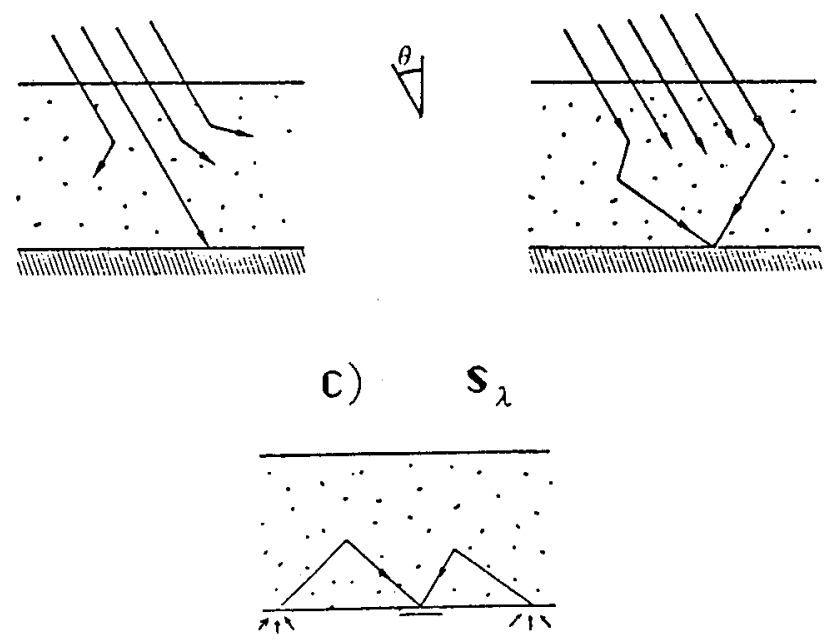

FIG. 1. Graphic representation of the spectral and angular dependent atmospheric parameters used to compute the mean atmospheric transmittances and reflectance. (a) TOA spectral path reflectance $\rho_{a \lambda}$; (b) atmospheric transmittance (direct + diffuse) $T_{d \lambda}$; and (c) atmospheric backscattering spectral reflection factor $s_{\lambda}$.

$$
T_{\mathrm{atm}}^{\sharp}(\theta)=\frac{\int_{0}^{\infty} d \lambda T_{d \lambda}(\theta) t_{g \lambda}(\theta) E_{0 \lambda}}{\int_{0}^{\infty} d \lambda E_{0 \lambda}},
$$

where $T_{d \lambda}$ is the total atmospheric transmittance of the atmosphere (direct plus diffuse, Fig. 1b). The term $t_{g \lambda}$ accounts for gaseous absorption, whereas the term $T_{d \lambda}$ accounts for molecular and aerosol scattering. The surface albedo, which represents photons not absorbed by the surface, is defined as

$$
A_{\text {sur }}(\theta)=\frac{\int_{0}^{\infty} d \lambda \rho_{s \lambda}(\theta) T_{d \lambda}(\theta) t_{g \lambda}(\theta) E_{0 \lambda}}{\int_{0}^{\infty} d \lambda T_{d \lambda}(\theta) t_{g \lambda}(\theta) E_{0 \lambda}},
$$

where $\rho_{s \lambda}$ is the spectral surface reflectance. This expression for $A_{\text {sur }}(\theta)$ indicates that $\rho_{s \lambda}$ is weighted by the downwelling spectral irradiance that reaches the surface in clear-sky conditions. Since varying atmo- 
spheric composition and/or sun angle modify the spectral distribution of downwelling irradiance at the surface, the surface broadband albedo cannot be considered as an intrinsic surface parameter. Clear-sky atmospheric variations, however, do not lead to dramatic changes in the surface albedo.

The total atmospheric transmittance, $T_{\mathrm{atm}}^{\Downarrow \pi}$, which characterizes the transparency of the atmosphere along the double, sun-to-surface, and surface-to-space path, is defined so that the shortwave flux reflected to space by the surface in clear-sky conditions is equal to $T_{\mathrm{atm}}^{\| \pi} A_{\text {sur }} \int_{0}^{\infty} d \lambda E_{0 \lambda}$; that is:

$$
\begin{aligned}
& T_{\mathrm{atm}}^{\Downarrow i 1}(\theta)= 2\left\langle\int _ { 0 } ^ { \infty } d \lambda \int _ { 0 } ^ { \pi / 2 } d \theta ^ { \prime } \left\{ T_{d \lambda}(\theta) T_{d \lambda}\left(\theta^{\prime}\right)\right.\right. \\
&\left.\times t_{g \lambda}(\theta) t_{g \lambda}\left(\theta^{\prime}\right) \rho_{s \lambda}(\theta) E_{0 \lambda} \cos \theta^{\prime} \sin \theta^{\prime}\right\} / \\
&\left.A_{\mathrm{sur}}(\theta) \int_{0}^{\infty} d \lambda E_{0 \lambda}\right) .
\end{aligned}
$$

We emphasize here that $T_{\text {atm }}^{4 \pi}$ is not an intrinsic atmospheric parameter since it depends on $\rho_{s \lambda}$. The $\rho_{s \lambda}$ dependence vanishes when $\rho_{s \lambda}$ is constant with wavelength, but this is generally not the case.

The spherical albedo of the atmosphere, which represents photons reflected by the surface and backscattered to the surface by the clear atmosphere, is weighted by the spectral irradiance reflected by the surface:

$$
\begin{array}{r}
A_{\mathrm{atm}}^{\Uparrow}(\theta)=\frac{1}{\pi}\left\langle\int _ { 0 } ^ { \infty } d \lambda \int _ { 0 } ^ { \pi / 2 } d \theta ^ { \prime } \int _ { 0 } ^ { 2 \pi } d \phi \left\{ s_{\lambda}\left(\theta^{\prime}, \phi\right)\right.\right. \\
\left.\times T_{d \lambda}(\theta) t_{g \lambda}(\theta) \rho_{s \lambda} E_{0 \lambda} \cos \theta^{\prime} \sin \theta^{\prime}\right\} / \\
\left.\int_{0}^{\lambda} d \lambda T_{d \lambda}(\theta) t_{g \lambda}(\theta) \rho_{s \lambda} E_{0 \lambda}\right),
\end{array}
$$

where $s_{\lambda}$ is the atmospheric backscattering spectral reflection factor (Fig. 1c). Considering a unit irradiance reflected by a flat Lambertian surface, $s_{\lambda}(\theta, \phi)$ is the radiance backscattered by the atmosphere to the surface in the direction $(\theta, \phi)$.

All the parameters, except $A_{\mathrm{atm}}^{\Downarrow}$ and $T_{\mathrm{atm}}^{\Downarrow}$, depend on the surface spectral reflectance. Equation (13) indicates that the spherical albedo is also a function of sun zenith angle. However, since the contribution of photons backscattered toward the surface is generally small ( $s_{\lambda}$ is on the order of $10^{-1}$ ) and $A_{\mathrm{atm}}^{\Uparrow}$ acts as a correction term, it is sufficient to assume that the spectral distributions of the surface-reflected irradiance and the TOA downwelling irradiance are similar. The expression for $A_{\mathrm{atm}}^{\hat{\mathrm{t}}}$, then, simplifies into:

$$
\begin{aligned}
A_{\mathrm{atm}}^{\hat{\mathrm{a}}} \approx \frac{1}{\pi} & {\left[\int_{0}^{\infty} d \lambda \int_{0}^{\pi / 2} d \theta^{\prime} \int_{0}^{2 \pi} d \phi s_{\lambda}\left(\theta^{\prime}, \phi\right)\right.} \\
& \left.\times E_{0 \lambda} \sin \left(\theta^{\prime}\right) \cos \left(\theta^{\prime}\right) / \int_{0}^{\infty} d \lambda E_{0 \lambda}\right] .
\end{aligned}
$$

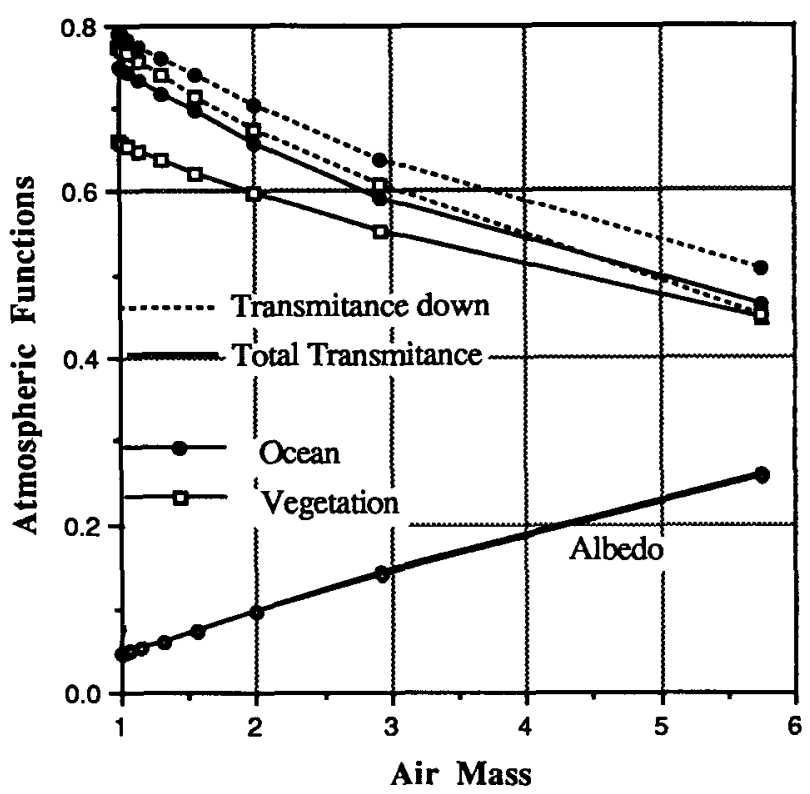

FIG. 2. Atmospheric albedo and transmittances (down and total) as a function of atmospheric path (air mass) for vegetation and ocean surfaces. The water vapor amount is $30 \mathrm{~kg} \mathrm{~m}^{-2}$ and the ozone content $0.3 \mathrm{~atm} \mathrm{~cm}$.

Using Eq. (14) instead of Eq. (13), therefore, makes $A_{\mathrm{atm}}^{\Uparrow}$ independent of surface reflectance and sun zenith angle.

To compute $A_{\text {atm }}^{\Downarrow}, T_{\mathrm{atm}}^{\Downarrow}, T_{\mathrm{atm}}^{\Downarrow \Uparrow}, A_{\mathrm{atm}}^{\Uparrow}$, and $A_{\text {sur }}$, we use the radiative transfer model of Tanré et al. (1990). Four surfaces types are considered, namely, vegetation, desert, ocean, and ice/snow. These surfaces are those identified in the ERBE S4 products (we do not consider the ambiguous "coast" surface type). For each surface, the overlying atmosphere is assumed to contain specific aerosol type and amount. Over vegetation, the aerosols are continental and their optical thickness is 0.179 (23 $\mathrm{km}$ visibility); over desert the aerosols are also continental but their optical thickness is $0.330(10 \mathrm{~km}$ visibility); over the ocean the aerosols are maritime and their optical thickness is 0.219 (23 km visibility); and over ice/snow the aerosols are maritime, but much less abundant (optical thickness of 0.080 or visibility of $300 \mathrm{~km}$ ). The aerosol models selected (continental, maritime) are mixtures of basic models (water soluble, dustlike, soot, oceanic) described in WCP-55 (1983); the optical thicknesses for the ERBE surface types are similar to those used by Staylor and Wilber (1990) to estimate global surface albedos from ERBE data. The spectral surface reflectances of vegetation, desert, and ocean are those specified in the Tanre et al. (1990) code, while the spectral surface reflectance of snow/ ice corresponds to a typical snow surface sample reported by Bowker et al. (1985).

For a molecular atmosphere, the model of Tanré et al. (1990) employs a modified first-order scattering approximation which accounts indirectly for multiple 

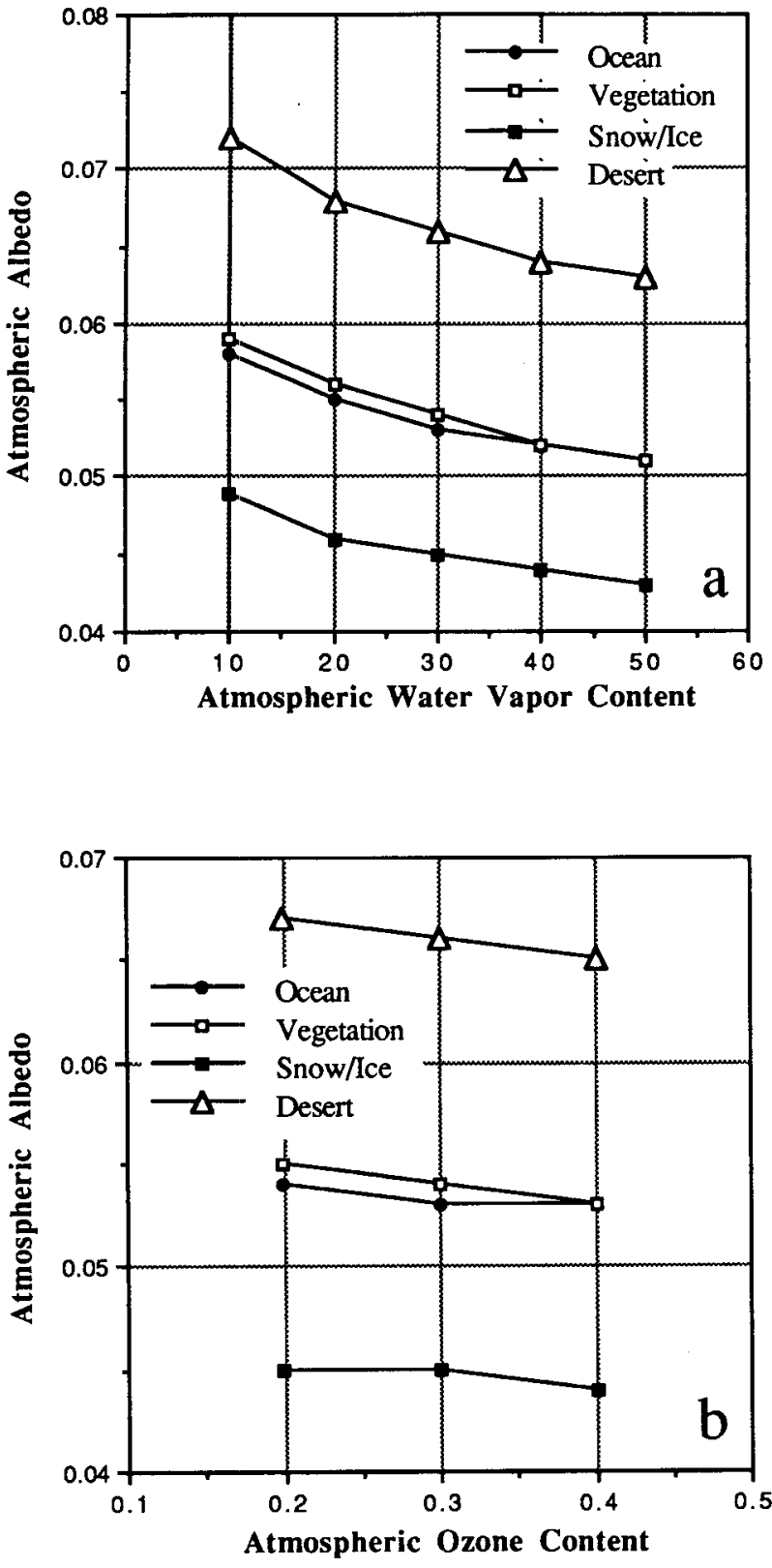

FIG. 3. Atmospheric albedo as a function of (a) water vapor amount and (b) ozone amount for ocean, vegetation, desert, and snow/ice surfaces. The sun zenith angle is $30^{\circ}$. In (a) the atmospheric ozone amount is $0.3 \mathrm{~atm} \mathrm{~cm}$; in (b) the water vapor amount is $30 \mathrm{~kg} \mathrm{~m}^{-2}$.

scattering. For aerosol scattering computations, the method of Sobolev (1963) is used, whereby multiple scattering is accounted for by developing the aerosol phase function as a sum of Legendre polynomials and retaining only the first two terms of the expansion. This treatment of scattering effects is accurate for $\theta<60^{\circ}$ (a few percent error when compared to exact calculations). At larger solar zenith angles, the error may become substantially larger, especially for $A_{\mathrm{atm}}^{\sharp}$ as the aerosol abundance increases. Furthermore, decoupling scattering and absorption effects in the model introduces significant additional errors at those angles (gaseous absorption becomes larger). At high latitudes, however, where solar elevations are generally low, the atmosphere is generally less abundant in aerosols and water vapor, which tends to reduce the model uncertainties associated with their effects. Yet the rather simple treatment of molecular scattering will affect the results significantly at high latitudes.

Fig. 2 shows $A_{\mathrm{atm}}^{\Downarrow}, T_{\mathrm{atm}}^{\Downarrow}$, and $T_{\mathrm{atm}}^{\Downarrow \Uparrow}$ as a function of
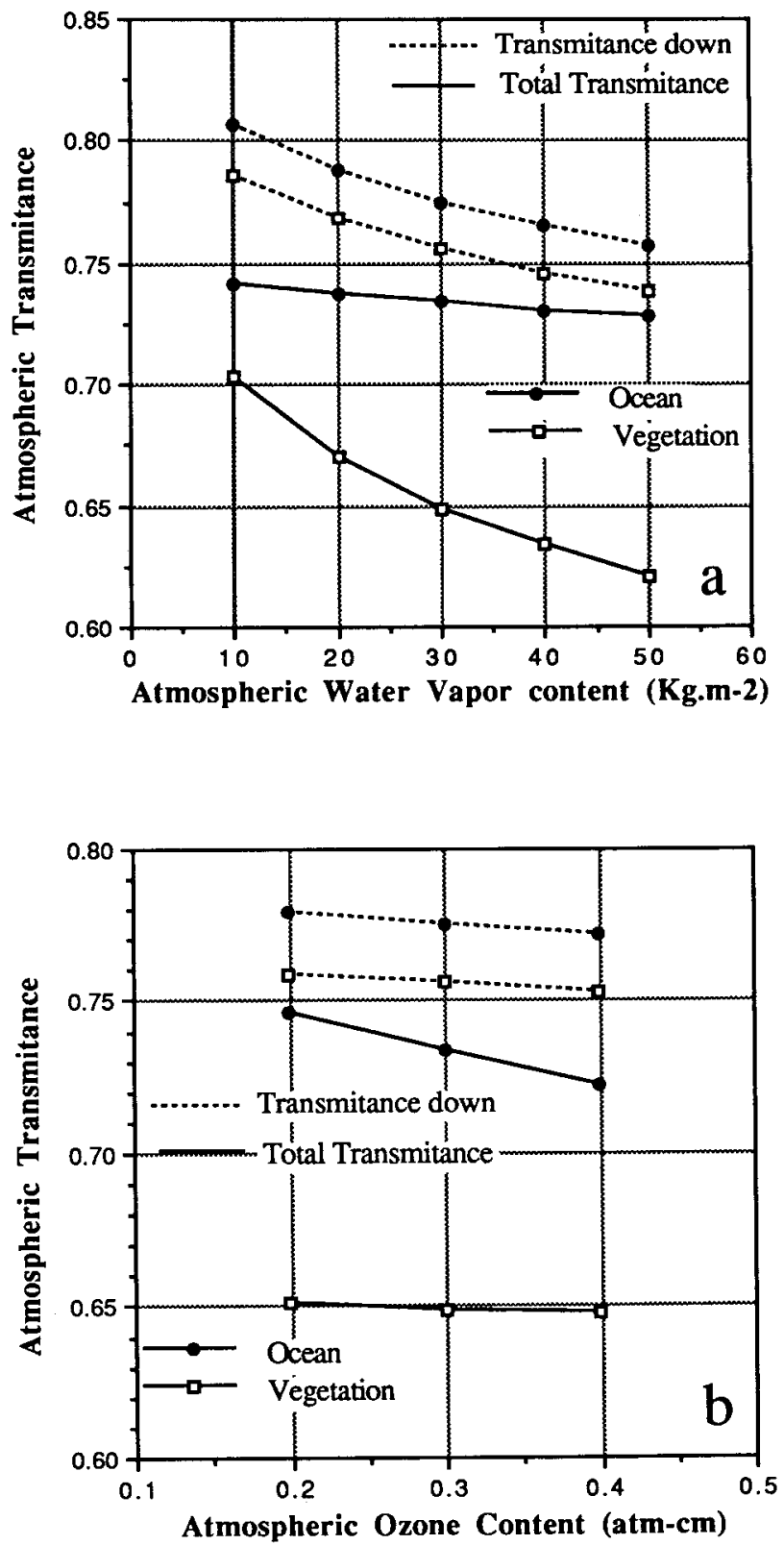

FlG. 4. Atmospheric transmittances (down and total) as a function of (a) water vapor amount and (b) ozone amount for vegetation and ocean surfaces. The solar zenith angle is $30^{\circ}$. (a) Atmospheric ozone content is $0.3 \mathrm{~atm}-\mathrm{cm}$; (b) water vapor amount is $30 \mathrm{~kg} \mathrm{~m}^{-2}$. 
TABLE 1. $A_{\mathrm{atm}}^{\|}, T_{\mathrm{atm}}^{\|}, T_{\mathrm{atm}}^{\sharp \mathrm{n}}$, and $A_{\mathrm{atm}}^{\|}$for vegetation, desert, ocean, and snow/ice cases. The atmosphere contains $30 \mathrm{~kg} \mathrm{~m}^{-2}$ of water vapor, $0.3 \mathrm{~atm} \mathrm{~cm}$ of ozone, and the sun zenith angle is $30^{\circ}$.

\begin{tabular}{lcccc}
\hline \hline Surface type & $A_{\text {atm }}^{\Downarrow}$ & $T_{\text {atm }}^{\Downarrow}$ & $T_{\text {atm }}^{\| \Uparrow}$ & $A_{\text {atm }}^{\dagger}$ \\
\hline Vegetation & 0.054 & 0.756 & 0.649 & 0.107 \\
Desert & 0.066 & 0.722 & 0.567 & 0.133 \\
Ocean & 0.053 & 0.775 & 0.734 & 0.110 \\
Snow/ice & 0.045 & 0.788 & 0.714 & 0.086 \\
\hline
\end{tabular}

air mass $(1 / \cos \theta)$ for vegetation and ocean surfaces ( $T_{\mathrm{atm}}^{\Downarrow}$ and $T_{\mathrm{atm}}^{\Downarrow \mathrm{H}}$ only). The water vapor and ozone amounts are fixed at $30 \mathrm{~kg} \mathrm{~m}^{-2}$ and $0.3 \mathrm{~atm} \mathrm{~cm}$, respectively. As expected, $A_{\mathrm{atm}}^{\Downarrow}$ increases with increasing air mass, whereas $T_{\mathrm{atm}}^{\Downarrow}$ and $T_{\mathrm{atm}}^{\Downarrow \| 1}$ decrease with increasing air mass. Since $T_{\mathrm{atm}}^{\mathrm{y}}$ involves a double atmospheric path, $T_{\mathrm{atm}}^{\Downarrow}<T_{\mathrm{atm}}^{\Downarrow}$. Owing to more abundant aerosols over vegetation, $T_{\mathrm{atm}}^{\Downarrow}$ and $T_{\mathrm{atm}}^{\Downarrow \Uparrow}$ are smaller over that surface.

Figures $3 \mathrm{a}$ and $3 \mathrm{~b}$ show the dependence of atmospheric albedo on water vapor and ozone contents. Water vapor and ozone absorb upwelling and downwelling radiation and therefore reduce atmospheric albedo. Similarly, the effect of increasing water vapor or ozone amount reduces atmospheric transmittance $\left(T_{\mathrm{a} m}^{\Downarrow \|}\right.$ and $\left.T_{\mathrm{atm}}^{\Downarrow}\right)$, as depicted in Figs. $4 \mathrm{a}$ and $4 \mathrm{~b}$. For the ocean surface, we note that the slope of variations is more negative for $T_{\mathrm{atm}}^{\| \wedge}$ than $T_{\mathrm{atm}}^{\Downarrow}$ in the case of ozone (Fig. 4b), but is less negative in the case of water vapor (Fig. $4 \mathrm{a}$ ). The reason is that the ocean is almost black at the wavelengths of strong water vapor absorption, but not so in the spectral region of ozone absorption. A similar dependence is obtained for snow/ice (not shown here), but the effect is reversed for vegetation and desert, a consequence of the higher surface reflectance in the near-infrared where water vapor absorbs radiation substantially.

Table 1 compares $A_{\mathrm{atm}}^{\Downarrow}, T_{\mathrm{atm}}^{\Downarrow}, T_{\mathrm{atm}}^{\Downarrow \|,}$, and $A_{\mathrm{atm}}^{\hat{\imath}}$ for the various surface types. The atmosphere contains 30 $\mathrm{kg} \mathrm{m}^{-2}$ of water vapor and $0.3 \mathrm{~atm} \mathrm{~cm}$ of ozone, and the sun zenith angle is $30^{\circ}$. The atmospheric albedo $A_{\text {atm }}^{\|}$is maximum over desert and minimum over snow/ice, with intermediate values over vegetation and ocean. This characterizes the effect of aerosols, in particular their optical thicknesses. Although the aerosol optical thickness is higher over the ocean than over vegetation ( 0.219 instead of 0.179$), A_{\mathrm{atm}}^{\sharp}$ is slightly higher over the latter. This is due to the maritime aerosols' higher anisotropy factor of the aerosol phase function (lower backscattering coefficient). Similarly, $T_{\mathrm{atm}}^{\Downarrow}$ is higher over ocean than over vegetation, the result of a lower backscattering coefficient and a higher single scattering albedo (close to 1). Note, furthermore, that the relative difference between $T_{\mathrm{atm}}^{\Downarrow}$ and $T_{\mathrm{atm}}^{\| / \mathrm{A}}$ is higher over desert and vegetation, a consequence of the combined action of increased aerosol amount and higher surface reflectance.

The $A_{\mathrm{atm}}$ values do not depart significantly from
0.1 , indicating that the effect of photons reflected by the surface and backscattered toward the surface will be to increase the surface solar irradiance by no more than approximately $10 \%$. In general (except over snow/ ice), however, the effect will be much smaller.

\section{c. Algorithm}

In order to reduce errors resulting from uncertainties on $A_{\text {sur }}, A_{\text {cld }}$, and $a_{\text {cld }}$, we deal with normalized cloud radiative forcings instead of shortwave fluxes. The normalized TOA and surface cloud radiative forcings are defined by:

$$
\begin{aligned}
\mathrm{CLD}_{\mathrm{TOA}} & =A_{\mathrm{TOA}}-A_{\mathrm{TOA}}^{\mathrm{clr}} \\
C_{\mathrm{TL}} & =\frac{F_{\mathrm{sur}}^{\mathrm{clr}-\mathrm{abs}}-F_{\mathrm{sur}-\mathrm{abs}}}{F_{\mathrm{TOA}}^{\sharp}} .
\end{aligned}
$$

Indeed, one can easily compute shortwave irradiance absorbed by the surface from surface radiative forcing and clear-sky shortwave irradiance, the latter being obtained from surface albedo, water vapor, ozone, and aerosol climatologies using Eq. (7) (see details in section 2a).

Our objective, therefore, is to find a simple expression relating $C L D_{\text {sur }}$ to $C L D_{\text {TOA }}$. Although the number of unknowns is equal to the number of equations, there is no simple analytical formula that connects the two cloud forcings. Consequently, we seek an empirical relation based on the model equations by simulating realistic geometric, atmospheric, and surface conditions.

For varying sun angles, atmospheric characteristics, and surface types we have computed CLD TOA $_{\text {and }}$ $C D_{\text {sur }}$ as a function of cloud albedo. Typical results are presented in Fig. 5. Sun zenith angle is $30^{\circ}$, water vapor and ozone amounts are $30 \mathrm{~kg} \mathrm{~m}^{-2}$ and $0.3 \mathrm{~atm}$ $\mathrm{cm}$, respectively, and aerosols are of continental type (visibility equal to $23 \mathrm{~km}$ ). For surface albedos lower than $40 \%$, the relationship between surface and TOA cloud forcings is virtually linear. This linearity has a fundamental consequence: inferring the surface cloud forcing from the TOA cloud forcing yields the same result whether the TOA observations are first averaged to deduce the surface parameter or used to deduce individual surface cloud forcings that are then averaged. This is true for spatial averages as well as temporal averages. Thus, once surface albedo is estimated, it is not necessary to determine whether a pixel is clear or cloudy or to consider each day separately.

To benefit from the implications of linearity discussed above, one needs to work with TOA irradiance measurements. Most satellite-borne radiation budget instruments measure radiance-not irradiance. Therefore, the data must be corrected for bidirectional effects using angular distribution functions that account for cloud cover within the field of view and, inevitably, introduce errors. In addition, since our algorithm requires an estimate of the surface albedo, clear scenes must be separated from cloudy ones. 


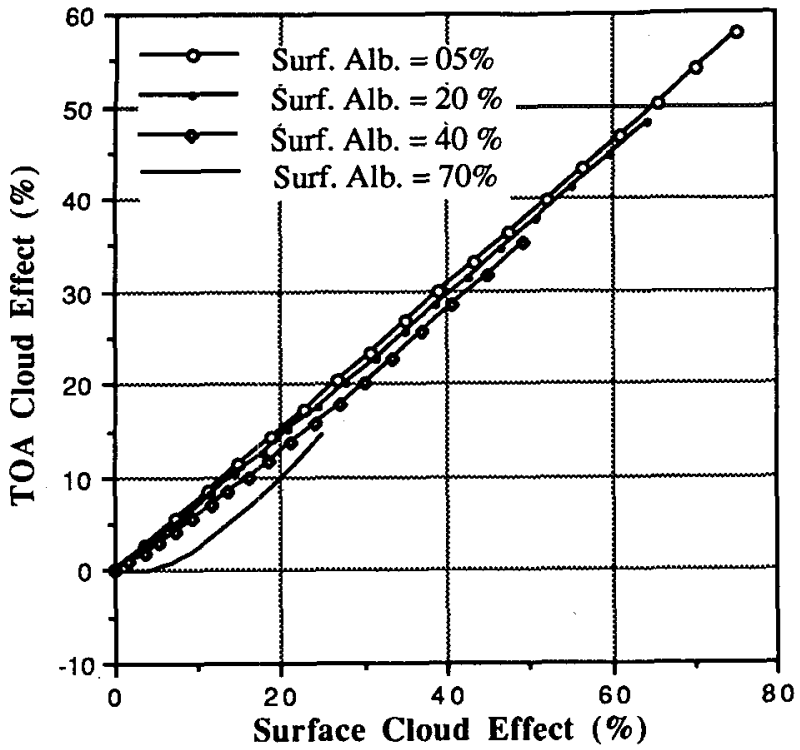

FIG. 5. TOA shortwave cloud forcing as a function of surface shortwave cloud forcing when varying the cloud albedo (the origin of the axes corresponds to the clear-sky case). The cloud forcing is given as a percentage of the TOA incoming solar irradiance. The four curves correspond to surface albedos of $5 \%, 20 \%, 40 \%$, and $70 \%$.

We note in Fig. 5 that linearity is not perfect, and departure from linearity increases with increasing surface albedo. Nonlinearity is the result of multiple reflections between the surface and clouds that tend to increase the flux absorbed at the surface and within clouds. For the largest surface albedos, the TOA cloud forcing becomes negative in the lower range of cloud albedos. It can be shown that such a situation occurs whenever the surface albedo is greater than $[1+\alpha$ $\left.-\left(\alpha^{2}+2 \alpha\right)\right]$, which is of the order of 0.65 . Welch and Wielicki (1989) have shown the same counterintuitive result, namely that including a cloud over a highly reflective surface may decrease the system albedo. In that case, because of multiple reflections between the surface and clouds, cloud/surface-increased absorption surpasses increased albedo due to the presence of the clouds and therefore reduces the TOA albedo. Our simple model, however, is probably not accurate in conditions of low-albedo clouds over highalbedo surfaces (i.e., snow/ice) because surface and cloud absorption both occur in the longwave part of the solar spectrum. Multiple reflections shift the spectral distribution of irradiance toward shorter wavelengths and consequently yield lower absorption; hence, the TOA albedo is larger than modeled. For high surface albedos, the nonlinearity in the relationship between TOA and surface cloud forcings is a potential problem for retrieving surface shortwave budgets over polar regions using our approach. Achieving good accuracy requires not averaging the TOA observations before doing the computations. Unfortunately, the sat- ellite data we intend to use, namely ERBE-derived irradiances in the $\mathrm{S} 4$ format, are monthly averages (see below).

In order to account for nonlinearities, we parameterize the relation between the surface and TOA cloud effects as:

$$
\mathrm{CLD}_{\mathrm{TOA}}=\beta \mathrm{CLD}_{\mathrm{SUR}}+\gamma \mathrm{CLD}_{\mathrm{SUR}}^{2}
$$

where $\beta$ and $\gamma$ are best-fit coefficients. These coefficients depend on sun zenith angle, atmospheric water vapor and ozone contents, and surface type. They have been precalculated for three ozone amounts $(0.1,0.2$, and $0.3 \mathrm{~atm} \mathrm{~cm})$, five water vapor amounts $(1,2,3,4,5$ $\mathrm{g} \mathrm{cm}^{-2}$ ), nine sun zenith angles ( 0 to $80^{\circ}$ by step of $10^{\circ}$ ), and four surface types (ocean, vegetation, snow $/$ ice, desert), and they are kept in a lookup table. The lookup table is small in size (a few Mbytes) and, hence, easily manageable. In our algorithm, aerosol type and amount do not define separate categories because they are associated with a particular surface type. For instance, over an oceanic surface the atmosphere contains standard maritime aerosols and is characterized by a 23-km visibility ( see section $2 \mathrm{~b}$ ).

Retrieving monthly surface shortwave irradiance is accomplished using ERBE S4 planetary albedo data. These data, in the form of monthly averages at 24 local times, are derived from instantaneous broadband radiance measurements, taking into account the anisotropy of the radiance reflected by the surface and clouds (see Barkstrom 1984). Our procedure is as follows: first we compute, for each of the $10082 \mathrm{~S} 4$ regions (each region is $2.5^{\circ}$ latitude $\times 2.5^{\circ}$ longitude) and the 24 local times, the sun zenith angle and determine the atmospheric water vapor and ozone amounts from a climatology, based on McClatchey et al.'s (1971) typical profiles. Then we use these parameters and the surface type (specified for each S4 region) to determine, also from precalculated values, the atmospheric functions $A_{\mathrm{atm}}^{\Uparrow}, A_{\mathrm{atm}}^{\sharp}, T_{\mathrm{atm}}^{\Uparrow}$, and $T_{\mathrm{atm}}^{\| \Uparrow}$. The ERBE S4 product "clear albedo" gives access to surface albedo using Eq. (6). Next we find $\beta$ and $\gamma$ in the lookup table and compute, using the values obtained for the coefficients, surface cloud forcing, which allows us to deduce, using Eqs. (7) and (16), net surface irradiance from cloud forcing. Finally we weight average the hourly values of surface albedo and cloud forcing, accounting for the relative importance of clear-sky surface irradiance at each local hour, and we integrate over the day the resulting hourly net surface flux.

\section{d. Discussion}

Over land, the spectral dependence of surface albedo is highly variable. Inferring broadband reflected flux from a narrowband radiance measurement, as is currently done using the Advanced Very High Resolution Radiometer (AVHRR) aboard the NOAA satellites or the Visible and Near Infrared Spin-Scan Radiometer 
(VISSR) aboard the GOES satellites, is then subject to uncertainty: The measurement cannot give information at wavelengths opaque to the sensor, and the amount of radiation originating from the missing spectral region may vary substantially with the type of atmosphere and surface [see also Cess and Vulis (1989)]. Although broadband measurements greatly reduce this uncertainty, they are not perfect either; similar TOA fluxes can be obtained with the same atmospheric characteristics, but different spectral surface albedos. Ancillary information about the spectral dependence of surface albedo is therefore needed. As mentioned in the Introduction, the problem of inferring net surface solar irradiance from TOA broadband albedo measurements is associated with estimating the atmospheric absorption. In strong absorption bands, very little radiation reaches the surface, and the surface albedo is not an important parameter. Elsewhere in the solar spectrum, radiation is weakly attenuated, particularly along the surface-to-sensor path sensitive to surface albedo. Total atmospheric absorption is consequently not very sensitive to the spectral dependence of surface albedo. More insight on this topic can certainly be gained from radiative transfer simulations of realistic surfaces topped with a constant atmosphere.

Let us now discuss the major approximations of our model. They are 1) using clear-sky conditions to compute atmospheric functions, although we know that clouds modify the spectral distribution of irradiance; 2 ) assuming that cloud reflectance is spectrally white; 3) using a crude model for cloud absorption; and 4) using climatological values for atmospheric water vapor, ozone, and aerosol amounts.

Since cloud absorption is mostly limited to the longer wavelengths of the solar spectrum, the presence of clouds shifts the spectral irradiance distribution toward shorter wavelengths. Since clear-sky atmospheric absorption mostly occurs above about $0.85 \mu \mathrm{m}$ (longer wavelengths), the modeled upwelling atmospheric transmittance is too large in cloudy conditions. It should be noted that water vapor absorption occurs first along the sun-to-cloud/surface path, that is, before encountering clouds. The strong absorption bands are already saturated, and the cloud effect on upwelling atmospheric transmittance is limited to the spectral region of weak absorption bands. On the other hand, the cloud effect on surface albedo, due to redistribution of spectral irradiance reaching the surface, is expected to be largest over vegetation. For this surface type, albedo increases dramatically above $0.7 \mu \mathrm{m}$. Clouds therefore tend to make surface albedo lower than in clear-sky conditions. Let us emphasize again that uncertainty in the relation between TOA and surface net shortwave fluxes results directly from uncertainties in atmospheric (clear and cloudy) absorption. Clouds affect atmospheric absorption along the upwelling path only and the effect is limited to weak absorption bands. We therefore have a tendency to overestimate atmo- spheric absorption, but the error is less consequential than that resulting from our crude modeling of cloud absorption.

Our model implicitly neglects the spectral dependence of clouds. Clouds are not spectrally white, however, and multiple cloud/surface reflections may change strongly the solar irradiance spectral distribution. Then, when surface albedo is high, our modeling of cloud/surface multiple reflections, as expressed in the denominator of the second term of Eq. (3), is inaccurate. This is confirmed by comparisons of our model results with those from radiative calculations using Stamnes et al.'s (1988) discrete ordinate code. The comparisons, made only for overcast conditions, show that our model is accurate (to a few percent) over the ocean whatever the cloud optical thickness. On the other hand, it is substantially in error over bright land surfaces (especially desert) when cloud optical thickness is large. The relative error is even larger over snowcovered surfaces. In that case, the error reaches $50 \%$, even when cloud optical thickness is as small as 5. Fortunately, the largest relative errors are associated with large cloud optical thicknesses and, therefore, small fluxes. When averaged over one month, thick cloud coverage contributes little to the mean surface flux. Still, the model is clearly less accurate over land than over the ocean.

We use a simple, linear relation between cloud reflectance and absorption. This is obviously a crude approximation, but we made that choice because large uncertainties remain in more complex parameterizations. Although our cloud absorption values have the correct order of magnitude, large relative errors are possible. A more precise parameterization could be included when theory and observations finally agree. It is worth noting that cloud absorption is a small fraction of cloud albedo and, therefore, the main effect of clouds on the shortwave radiative budget at the surface is through reflection rather than absorption.

Apart from clouds, atmospheric absorption is mostly governed by water vapor and ozone amounts. In our algorithm, these parameters are obtained from a climatology. Since atmospheric absorption is the difference between TOA and surface shortwave budgets, uncertainties in water vapor and ozone amounts directly impact surface shortwave budget estimates. We can evaluate the resulting errors from the sensitivity of atmospheric (clear sky) absorption to water vapor and ozone amounts. Taking the uncertainty in water vapor amount at $10 \mathrm{~kg} \mathrm{~m}^{-2}$ and in ozone amount at $0.1 \mathrm{~cm}$ atm, the errors in atmospheric absorption are typically 0.025 and 0.005 , respectively. These errors are small compared to errors in cloud absorption, even insignificant in the case of ozone.

Because the atmospheric scattering approximations become less valid as the optical path increases, our radiative transfer computations loose accuracy when the solar zenith angle is larger than $60^{\circ}$. How does this 
affect surface absorption estimates? In tropical regions, or midlatitudes during summer, shortwave radiation incoming at large sun zenith angles, which occur during a small fraction of the day, does not contribute greatly to daily averaged shortwave irradiance. Thus, model uncertainties at these angles are not expected to degrade monthly averaged values significantly. In polar or midlatitude regions during winter, on the contrary, the sun zenith angle is in the vicinity of, or larger than, $60^{\circ}$ for most of the day. We can therefore expect larger relative errors in these regions. Note that the TOA measurement tells us how much shortwave radiation is absorbed by the surface/atmosphere system and, since atmospheric absorption variability is small, uncertainties in modeling atmospheric absorption may have little impact on the net surface flux estimate. On the other hand, the surface albedo estimate may not be as accurate when the sun zenith angle is as large as the atmospheric albedo $A_{\mathrm{atm}}^{\Downarrow}$, which can be of the same order of magnitude as the TOA albedo $A_{\mathrm{TOA}}^{\mathrm{clr}}$ [Eq. (6)].

\section{Comparisons with other satellite estimates}

\section{a. Description of the estimate method for ISCCP data}

As explained above, there is no absolute way to validate our method. We can gain confidence in its results, however, if these are comparable to those obtained with other satellite data and retrieval methods. We present here a comparison of our results to those obtained from computations based on International Satellite Cloud Climatology Project (ISCCP) products, namely TOA visible and near-infrared radiances sampled every 3 hours at 32-km resolution (B3 format). The retrieval method is that of Gautier et al. (1980). However, from earlier validations of a similar approach with higherresolution data (e.g., Gautier and Katsaros 1984; Gautier 1988), the uncertainty is expected to be on the order of $10 \%-12 \%$, with a slightly high bias. Note that this uncertainty is reduced when considering monthly integrated values. Additional but limited comparisons performed as part of the First ISCCP Regional Experiment (FIRE) between surface measurements and satellite-based computations, suggest uncertainties of the order of several percent (Whitlock et al. 1990) and sometimes larger in the case of inhomogeneous cloud conditions.

Using ISCCP-B3 radiances, the procedure to compute net surface shortwave irradiance first requires separating clear and cloudy pixels. This is accomplished using a threshold technique. Over the oceans, where the comparisons of ERBE- and ISCCP-based estimates are made, surface albedo is known and defines the threshold. Once the pixel's nature (clear or cloudy) is determined, radiative transfer models are applied accordingly. In clear-sky conditions, the shortwave flux absorbed by the surface, $F_{\text {sur-abs, }}^{\text {clr }}$, is computed with a simplified code, equivalent to the $5 \mathrm{~S}$ code, which uses climatological values of water vapor and aerosols (see Gautier et al. 1980). In cloudy conditions, the shortwave flux absorbed by the surface, $F_{\text {sur-abs }}^{\text {cld }}$, is computed as

$$
F_{\text {sur-abs }}^{\mathrm{cld}}=F_{\text {sur-abs }}^{\mathrm{clr}}\left(1-A_{\mathrm{cld}}-a_{\mathrm{cld}}\right) /\left(1-A_{\mathrm{cld}} A_{\text {sur }}\right),
$$

where $A_{\text {cld }}$ is inferred from the B3 radiance by solving a quadratic equation and $a_{\text {cld }}$ is taken as a fraction of $A_{\text {cld }}$ (see Gautier et al. 1980). Here again, the term $A_{\text {cld }} A_{\text {sur }}$ is introduced to account for multiple cloudsurface reflections. In the last step, the instantaneous flux estimates obtained by applying the clear-sky model and Eq. (18) are integrated over the day and averaged temporally and spatially to yield monthly estimates at the $2.5^{\circ} \times 2.5^{\circ} \mathrm{ERBE}$ resolution.

\section{b. Comparisons}

The comparisons presented here are limited to the tropical $\left(30^{\circ} \mathrm{N}-30^{\circ} \mathrm{S}\right)$ Pacific Ocean. The ISCCP data are derived from shortwave measurements of two geostationary satellites: GOES-West and GMS. Based on available ISCCP measurements at the time of this study, we processed all months of 1986 except for December. As for ERBE, we have processed all months of 1986 except for September, November, and December. All months of 1985, except for January and April, are also available for further interannual comparisons.

Table 2 summarizes the results of these first intervalidations. We give the correlation of the ERBE- and geostationary satellite-based estimates for each month of 1986 . We also show the correlation obtained when comparing ISCCP monthly estimates of 1986 with ERBE estimates of 1985 .

The two monthly estimates are very similar. The correlation coefficients, significant at the $99 \%$ confidence level, range between 0.92 and 0.97 . The statistics, however, reveal a bias on the order of $15 \mathrm{~W} \mathrm{~m}^{-2}$ between the two types of estimates (ERBE estimates are higher). The monthly standard deviations are also on the order of $15 \mathrm{~W} \mathrm{~m}^{-2}$. The correlation obtained with different year estimates is useful as a comparison. The increase in correlation, from ERBE-85 to ERBE-86 compared to ISCCP-86, indicates that the agreement is not only climatological. Similar year-to-year variations are indeed depicted with the two satellite-based methods.

We then study the spatial distribution of the differences between the two fields. It appears that the differences increase with the geostationary satellite viewing angle (ISCCP measurements). A scatterplot of the differences as a function of the geostationary satellite viewing angle (Fig. 6) confirms this finding. The mean difference between the two fields increases almost linearly with the viewing angle. A best linear fit through the points shows a slope of $0.41 \mathrm{~W} \mathrm{~m}^{-2} \mathrm{deg}^{-1}$ and a negligible intercept. Thus, there is no bias between the 
two estimates over the subsatellite areas, but the bias is up to $25 \mathrm{~W} \mathrm{~m}^{-2}$ when the viewing angle is $60^{\circ}$. If we correct the ISCCP estimates for the viewing angle (i.e., we add $0.41 \mathrm{~W} \mathrm{~m}^{-2}$ per degree of zenith angle), we remove the bias between the two datasets and the rms difference, computed over the nine available months, is then reduced to $12.4 \mathrm{~W} \mathrm{~m}^{-2}$.

The two methods compared in this section rely on the same physical basis. On the other hand, the data they use are very different. They differ on the spectral width of the measurements, their spatial resolution, and their temporal coverage. Thus, the agreement found between the two fields is surprisingly good. The slight bias related to the viewing geometry needs to be solved. Bates and Gautier (1989) suggested a simple correction for the angular effects based on the hypothesis that the observed cloudiness increases with the viewing angle. This correction, however, depends on the cloud geometry, which is an unknown. We note that in the case of plane-parallel cloud cover, no correction need be applied. On the other hand, the anisotropy of cloud field reflectance is partly accounted for in the ERBE but not the ISCCP data. This may explain the bias that we corrected empirically.

\section{Results and analysis}

\section{a. Shortwave irradiance}

Figure 7 shows global maps of the net surface solar irradiance in January, April, July, and October 1986. The effect of changes in sun zenith angle are well depicted. Net surface shortwave irradiance generally decreases as latitude increases, with the meridional gradient more pronounced in the winter hemisphere. Maximum values of $310-320 \mathrm{~W} \mathrm{~m}^{-2}$ are encountered in the tropics during the four selected months and in the Mediterranean Sea in July. In January and July in the antarctic and arctic polar regions, respectively, even though the sun is always above the horizon and the

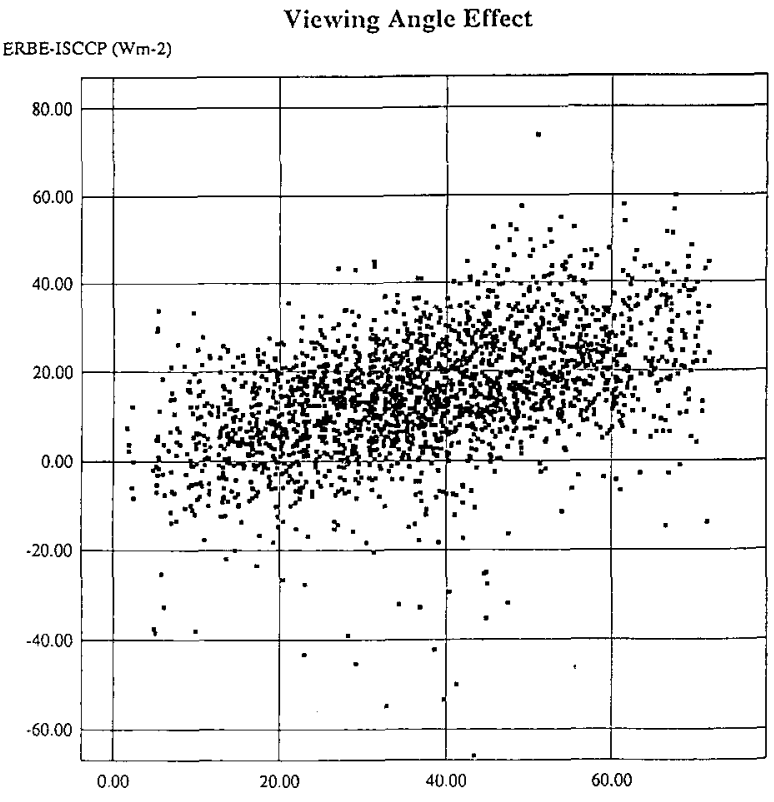

FIG. 6. Scatterplot of the surface flux estimate differences derived from ERBE data and ISCCP data, as a function of the geostationary satellite viewing angle (ISCCP data).

mean TOA incoming shortwave irradiance is as large as in the tropics, the net surface solar irradiance does not surpass a few tens of watts per square meter. This is due to particularly high cloudiness and surface albedo in those regions. The contrast between land and ocean is noticeable, a direct consequence of higher surface albedos over land. Over desert areas, particularly northwest Africa (Sahara), incoming shortwave irradiance is high, but as a result of relatively high surface albedo, the amount of shortwave energy penetrating the surface is substantially reduced. As expected, the ITCZ, relatively thin and close to the equator in Jan-

TABLE 2. Statistical comparison of the ERBE and ISCCP surface flux estimates. In the second column the correlation between the two types of estimates are given for various months of 1986. In the third column, the correlation is computed between ERBE-based estimates for 1985 and ISCCP-based estimates for the corresponding month of 1986 . The bias and the standard deviation of the two fields are then given for 1986. "Slope" is the mean slope of their difference as a function of the geostationary satellite viewing angle. RMS difference of the ERBE-based estimates and the ISCCP values after correction for the viewing angle effect.

\begin{tabular}{|c|c|c|c|c|c|c|}
\hline Month & $\begin{array}{l}\text { Corr. } \\
86 / 86\end{array}$ & $\begin{array}{l}\text { Corr. } \\
85 / 86\end{array}$ & $\begin{array}{c}\text { Bias } \\
\left(\mathrm{W} \mathrm{m}^{-2}\right)\end{array}$ & $\begin{array}{l}\text { Std. dev. } \\
\left(\mathrm{W} \mathrm{m}^{-2}\right)\end{array}$ & $\begin{array}{c}\text { Slope } \\
\left(\mathrm{W} \mathrm{m}^{-2} \mathrm{deg}^{-1}\right)\end{array}$ & $\begin{array}{l}\mathrm{Rms}_{\mathrm{cor}} \\
\left(\mathrm{W} \mathrm{m}^{-2}\right)\end{array}$ \\
\hline Jan & 0.97 & - & 23.2 & 12.8 & 0.529 & 9.6 \\
\hline Feb & 0.94 & 0.79 & 21.5 & 15.0 & 0.506 & 12.6 \\
\hline Mar & 0.92 & 0.57 & 21.1 & 12.8 & 0.340 & 11.6 \\
\hline Apr & 0.95 & - & 14.8 & 12.1 & 0.305 & 11.1 \\
\hline May & 0.97 & 0.90 & 10.1 & 10.9 & 0.293 & 9.8 \\
\hline Jun & 0.97 & 0.93 & 11.5 & 13.0 & 0.311 & 12.1 \\
\hline Jul & 0.96 & 0.91 & 10.5 & 13.1 & 0.413 & 11.6 \\
\hline Aug & 0.92 & 0.74 & 9.5 & 12.9 & 0.443 & 11.3 \\
\hline Oct & 0.94 & 0.83 & 12.9 & 13.6 & 0.508 & 11.6 \\
\hline Yearly & 0.95 & 0.84 & 15.1 & 13.9 & 0.409 & 12.4 \\
\hline
\end{tabular}




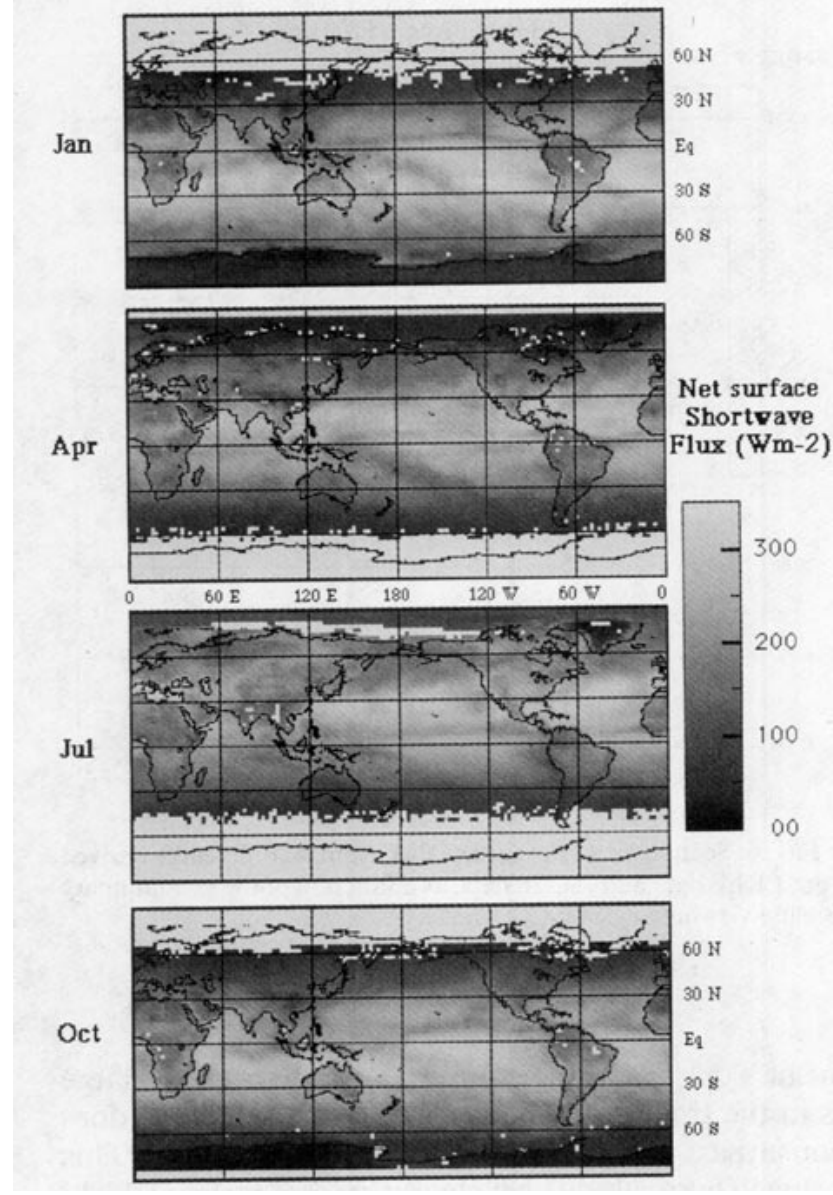

FIG. 7. Mean net surface solar irradiance during January, April, July, and October 1986. Regions where values are missing are indicated in white.

uary, has broadened and moved northward in July, and surface shortwave irradiance varies accordingly. The South Pacific convergence zone (SPCZ), characterized by a well-marked band of relatively low shortwave irradiance values in January, is less distinct and located more westward in July. As the Indian monsoon develops, net surface solar irradiance in the Arabian Sea and over the Indian continent, which was high in April (about $300 \mathrm{~W} \mathrm{~m}^{-2}$ ), is drastically reduced in July (values as low as $100 \mathrm{~W} \mathrm{~m}^{-2}$ ). Thus, the spatial and temporal features of net surface shortwave irradiance variability associated with major atmospheric phenomena are retrieved in the computed fields.

Since 1986 was a rather normal year (no El NiñoSouthern Oscillation ), and since the El Niño-Southern Oscillation occurs every 4 years on average, the net surface shortwave irradiance values obtained may be compared to those based on data from ships of opportunity. Among the global climatologies available, the climatology of Esbensen and Kushnir (1981) is rather comprehensive. Furthermore, it is commonly used to force ocean circulation models. Comparing the results of Fig. 7 with those of Esbensen and Kushnir, we find that the Esbensen and Kushnir values are generally lower, by as much as $80 \mathrm{~W} \mathrm{~m}^{-2}$ in the tropical and Atlantic oceans. It has already been noted by several authors, in particular Dobson and Smith (1989), that the formula used by Esbensen and Kushnir to compute insolation yields values substantially lower than those measured (typically $20 \%-30 \%$ ). Furthermore, satellite-based datasets (e.g., Gautier 1988; Arino 1990; Chertock et al. 1991) have provided results that are similar to our estimates over the ocean. The interesting point here is that the Esbensen and Kushnir values, when used in ocean insolation models, yield realistic sea surface temperature predictions. The underestimation of net surface solar irradiance must therefore be compensated for by an underestimation of turbulent (latent, sensible) and/or longwave radiative fluxes.

\section{b. Cloud parameter}

The cloud parameter is defined as the ratio of the surface cloud effect, that is, the surface net shortwave reduction due to clouds, $F_{\text {sur-abs }}^{\text {clr }}-F_{\text {sur-abs, }}$, and the clear-sky net surface irradiance, $F_{\text {sur-abs. }}^{\text {clr }}$ This cloud parameter, unlike the cloud radiative forcing introduced by Ramanathan (1986), minimizes the sun zenith angle effects. Figure 8 shows global maps of the monthly cloud parameter in January, April, July, and October 1986. Although the gross patterns are similar to those of the corresponding irradiance fields (Fig. 7), several new features appear in Fig. 8. For instance, the cloud parameter is higher in the midlatitude regions of storm tracks than in the ITCZ, indicating that on average clouds are more efficient at blocking shortwave radiation at the storm track latitudes, even though they are more reflecting in the ITCZ. In January, the cloud parameter is maximum around $70^{\circ} \mathrm{S}$ where cloudiness is high. Above $70^{\circ}-75^{\circ} \mathrm{S}$, the parameter decreases. The minimum of net surface solar irradiance observed in this region (Fig. 7) is therefore not due to increased cloudiness but to other parameters, most notably surface albedo. In April, a relative minimum is observed around $75^{\circ} \mathrm{S}$, indicating clearer skies. The subtropical highs, associated with low cloudiness and low cloud parameter, stand out well, and are flanked westward by higher values characterizing regions of subsidence (large-scale stratocumulus).

Figure 9 shows the cloud parameter latitudinal distribution for January, April, July, and October 1986. Averages over land (desert, vegetation, and snow/ice ERBE surface types) and ocean are indicated separately, as is the mean latitudinal value. As expected, we generally observe cloud parameter maxima in the equatorial/tropical region and around $50^{\circ}-60^{\circ}$ (region of storm tracks) and minima around $20^{\circ}-30^{\circ}$ (regions of subtropical highs over the ocean ). In April, a localized minimum around $70^{\circ} \mathrm{N}$ is also observed, resulting from a decreased cloud effect over most of the latitude 


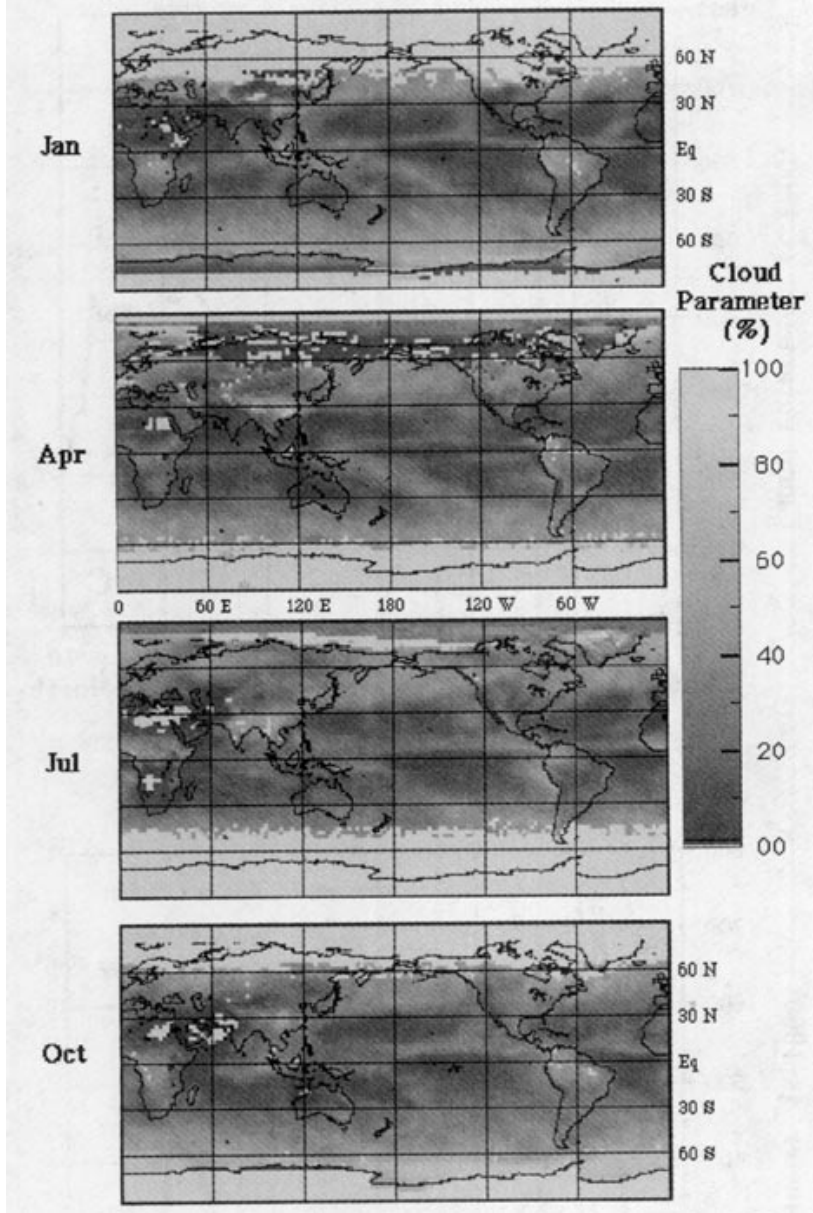

FIG. 8. Mean cloud parameter during January, April, July, and October 1986. The cloud parameter is defined as the ratio of the surface cloud effect, that is, the net shortwave irradiance reduction due to clouds, and the clear-sky net surface shortwave irradiance. Regions where values are missing are indicated in white.

band, as can be observed on the global map. Over the ocean at this latitude, however, the cloud parameter remains high, but the high oceanic values have little impact on the global average because land largely dominates at $70^{\circ} \mathrm{N}$. An interesting feature is the difference between ocean and land cloud parameters in the equatorial and tropical regions. The values are generally much higher over land and within $20^{\circ}-30^{\circ}$ of the equator. The maximum near $5^{\circ} \mathrm{N}$ in July over land has moved to $10^{\circ} \mathrm{S}$ in January. This might be attributed to the diurnal convection over humid equatorial areas. Land and ocean cloud parameters exhibit maximum values at approximately the same latitude in July and correspond to the well-developed ITCZ and the mature phase of the summer monsoon. For the other months, increased cloudiness over the African and South American continents south of the equator contributes to displacing the cloud parameter maximum to Southern Hemisphere latitudes, whereas the ITCZ effect over the ocean is depicted as a maximum north of the equa- tor. Another maximum around $10^{\circ} \mathrm{S}$ is also observed over the ocean in January, April, October, and, to a lesser extent, in July, and is associated with the SPCZ.

\section{c. Surface albedo}

Surface albedo maps for January, April, July, and October 1986 are presented in Fig. 10. Over the ocean, the values generally do not exceed 0.06 , although they may reach 0.1 locally. The higher values, however, may result from uncertainties in the cloud screening techniques applied to the ERBE data. Apart from the polar regions, where values are as high as 0.9 in July or January depending on the hemisphere, the Sahara and Arabia deserts exhibit the highest albedos, with values reaching 0.5 . In these regions, the seasonal change in surface albedo is small, in contrast with high-latitude regions where, because of winter snow/ice, the summer-winter differences can exceed 0.8 .

Figure 11 shows annually and zonally averaged surface albedos over land (vegetation, desert, and snow/ ice surface types), ocean, and all surfaces. As mentioned above, the values over the ocean are small at all latitudes, and they vary little with latitude. Note that the small kink between $60^{\circ}$ and $70^{\circ} \mathrm{N}$ corresponds to a mostly land-covered latitude band and is therefore not significant. Over land, on the contrary, the values change drastically with latitude. The maximum values are obtained at high latitude where land is often covered by snow. The "zero" value around $60^{\circ} \mathrm{S}$ is only the manifestation of an absence of landmasses in this latitude band. Note the significantly higher values in the antarctic polar regions than in the arctic polar regions, which indicates more ice-covered areas. Two relative maxima at $20^{\circ} \mathrm{N}$ and $25^{\circ} \mathrm{S}$ are clearly depicted and correspond to the relatively more reflective deserts (Sahara and Arabian in the Northern Hemisphere; Australia, South Africa in the Southern Hemisphere). At $25^{\circ} \mathrm{S}$, however, the maximum surface albedo value is 0.2 whereas at $20^{\circ} \mathrm{N}$ it reaches 0.33 , the result of more reflective deserts in the Northern Hemisphere as was noted on the global maps. Since ocean values are fairly constant, the mean latitudinal albedo variations over the ocean follow those over land, but are also influenced by the ratio of land and ocean areas.

\section{Conclusions}

One of the main drawbacks of our ERBE-based method when compared to current satellite methods is that it cannot be validated directly. The spatial and temporal resolution of the $\mathrm{S} 4$ data, $2.5^{\circ}$ and one month, although adapted to most climate studies, does not allow a direct comparison with in situ measurements. Other satellite methods, in particular those using instruments aboard geostationary satellites, which provide higher temporal and spatial resolution estimates, have been developed and validated against 

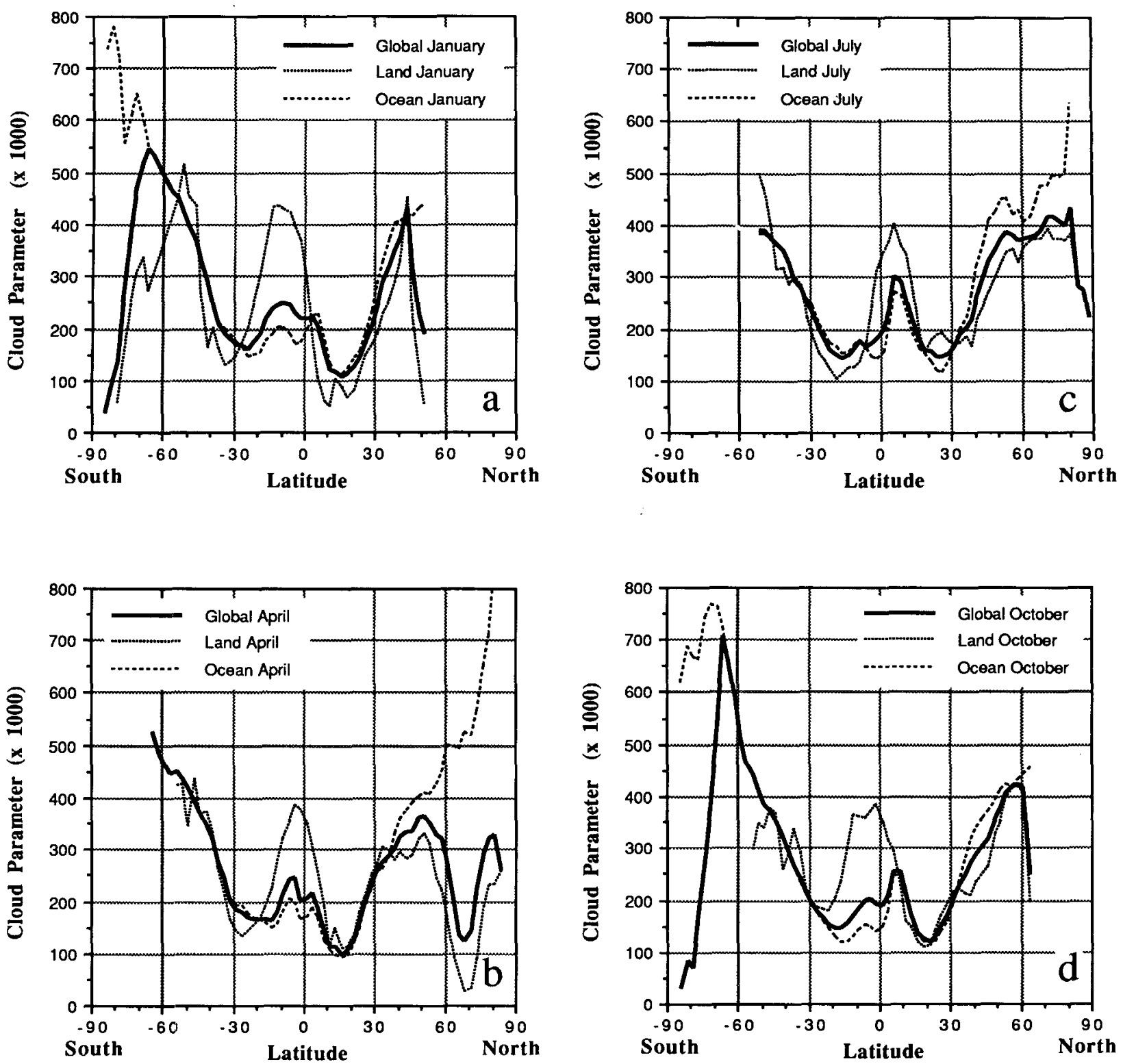

FIG. 9. Cloud parameter latitudinal averages during (a) January, (b) April, (c) July, and (d) October 1986.

The mean for all surfaces is given as well as for the ocean and land (vegetation, desert, and snow/ice).

carefully taken concomitant in situ measurements. It is then possible to compare the results of our method with those of the validated methods. However, the global products obtained using these methods might not be as precise as the local validation studies suggest because the model parameters are often "tuned up" for the validations, which cannot be done for global products. The Wisconsin Surface Radiation Budget intercomparison study (Whitlock et al. 1990) has concluded that most satellite methods available to estimate surface solar irradiance yield satisfactory results when compared to local in situ measurements. Yet, the global net shortwave irradiance maps produced by the various methods exhibit large discrepancies (Charlock 1991, personal communication ).

Aware of the limitations, we have nonetheless compared the ERBE-based net surface shortwave irradiance estimates to those obtained from ISCCP B3 data. The comparisons, performed only over the tropical Pacific Ocean, have shown a strong agreement (with high correlation coefficients) between the two types of estimates. We were able to trace a slight bias on the ISCCPbased estimates; this bias is a function of the satellite viewing angle. Over land and snow/ice surfaces, owing to our crude modeling of the spectral dependence of the TOA albedo and its effects on multiple cloud-sur- 
face interactions, theoretical calculations suggest that ERBE-based estimates may be biased low, especially over snow/ice and when clouds are optically thick.

The proposed method should, however, be at least as accurate as other satellite methods. We can even expect a better accuracy since no narrowband to broadband conversion of the measurements is necessary. The method's main advantage is that the same set of instruments monitors the entire earth, which removes intercalibration issues. Since all the necessary radiative transfer computations are performed once and for all, the method is easily applicable and computationally efficient. It is well adapted to produce global fields of net surface shortwave irradiance, which can then be used to force or to validate GCMs.

Examination of our method's products has revealed the method's capability to characterize the shortwave irradiance signature of the main climate, allowing for interannual comparisons. A comparison of the years 1985 and 1986 (not shown here) has indicated rather large differences in the cloud parameter and surface

Jan

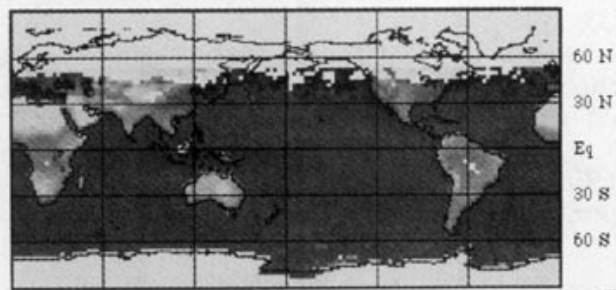

Surface

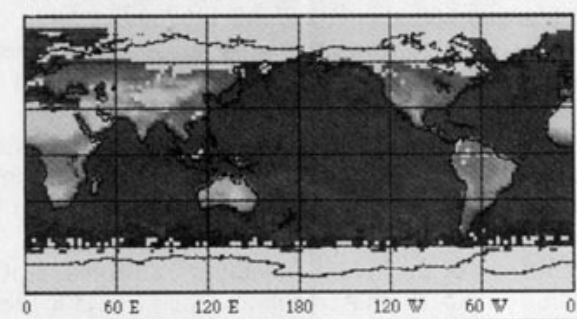

Albedo (\%)

Apr

Jul
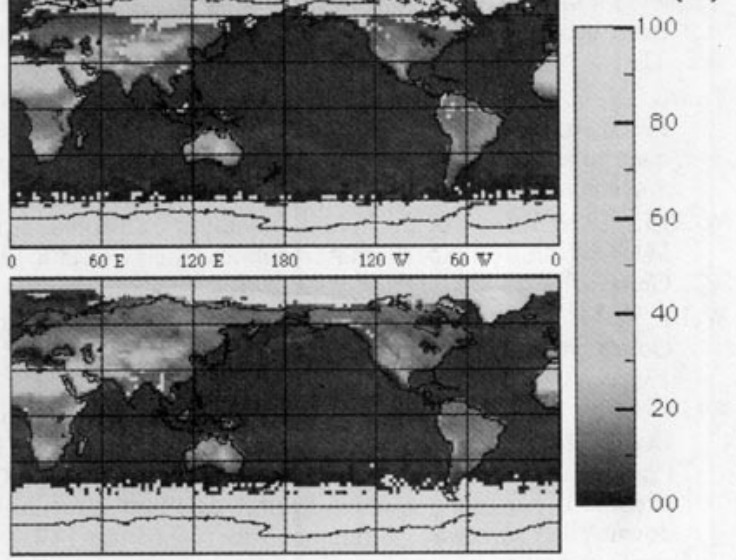

Oct

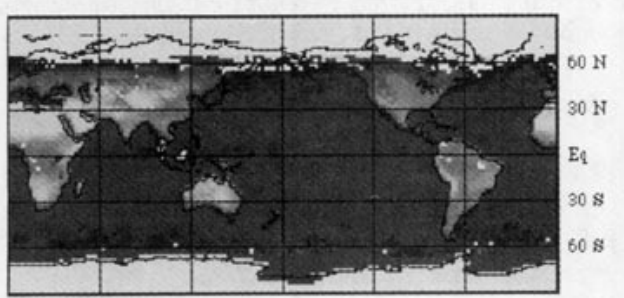

FIG. 10. Mean surface albedo during January, April, July, and October 1986. Regions where values are missing are indicated in white.

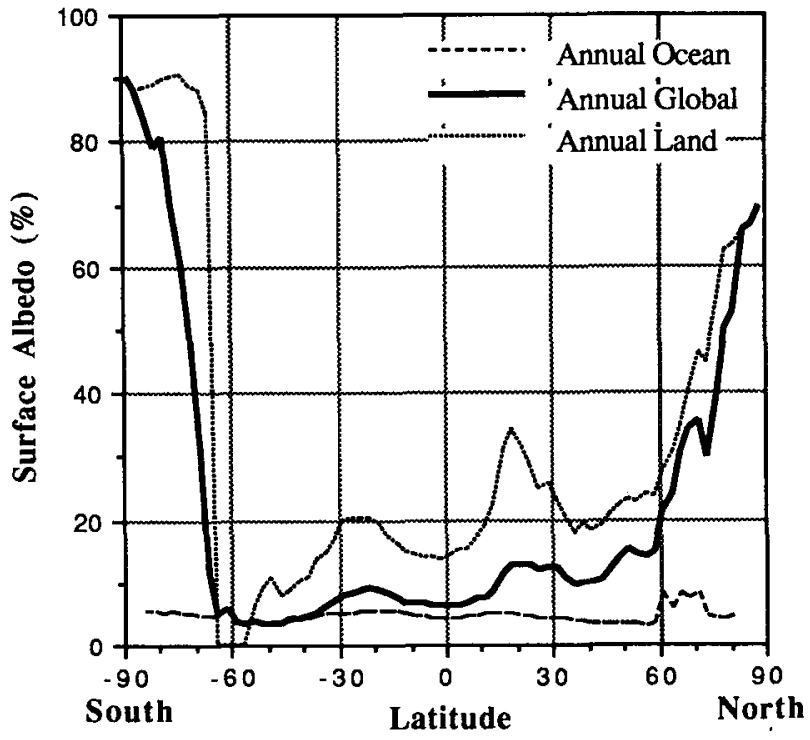

FIG. 11. Annually and latitudinally averaged surface albedo. The mean for all surfaces is given as well as for the ocean and land (vegetation, desert, and snow/ice).

fluxes, but these differences have not yet been interpreted satisfactorily.

We have computed and discussed the values of a cloud parameter, defined as the surface cloud forcing normalized by the clear-sky net surface shortwave irradiance. Defined this way, the cloud parameter substantially reduces the large sun zenith angle dependence that dominates the radiation charts and, therefore, is a good indicator of the effects of clouds on surface shortwave irradiance (cloud thickness and spatial coverage). Latitudinal averages of this cloud parameter show large variations. In equatorial regions, a local maximum characteristic of the ITCZ occurs over the ocean, and a much stronger maximum is observed over land because of enhanced convection. In the two tropics, at the downward branch location of Hadley cells, the cloud parameter exhibits a minimum and is of the order of $10 \%-15 \%$. Some ocean-land differences are of unclear origin, and the minimum is generally weaker in the Southern Hemisphere than in the Northern Hemisphere. In midlatitude regions, the cloud parameter increases toward the pole and is slightly larger over the ocean than over land. In April, a pronounced cloud parameter minimum is located in most of the $60^{\circ}-$ $70^{\circ} \mathrm{N}$ latitude band, but its occurrence may not be characteristic of the April situation during other years.

Acknowledgments. We wish to thank Terry Figel and Tao Wang for their contributions to the comparison with ISCCP estimates. This work has been supported in part by the National Aeronautics and Space Administration (Grant Number G-NASA NAG-5-236 and Number NAGW-2964), the National Oceanic and Atmospheric Administration (Grant Number 
NA86AA-D-AC051 and NA16RC0524), The National Science Foundation (Grant Number ATM84-13953), and the California Space Institute (Grant Number CS81-85). Computer resources have been supplied, in part, by the California Space Institute, Scripps Institution of Oceanography. Images have been produced with the Macintosh ${ }^{\mathrm{TM}}$ image processing software developed by the National Center for Supercomputing Applications at the University of Illinois at UrbanaChampaign.

\section{REFERENCES}

Arino, O., 1990: Albedo de Surface et Bilan Radiatif de Courtes Longueur d'Ondes. Doctoral dissertation, Institut National Polytechnique de Toulouse, $205 \mathrm{pp}$.

Bates, J., and C. Gautier, 1989: Interaction between net shortwave flux and sea surface temperature. J. Appl. Meteor., 28, 43-51.

Barkstrom, B. R., 1984: The Earth Radiation Budget Experiment (ERBE). Bull. Amer. Meteor. Soc., 65, 1170-1185.

Bowker, D. E., R. E. Davis, D. L. Myrick, K. Stacy, and W. T. Jones, 1985: Spectral Reflectances of Natural Targets for Use in Remote Sensing Studies. NASA Ref. Pub. No. 1139, $181 \mathrm{pp.}$

Bréon, F. M., 1992: Reflectance of broken cloud fields: Modelization and parameterization. J. Atmos. Sci., 49, 1221-1232.

Cess, R. D., and I. L. Vullis, 1989: Inferring surface solar absorption from broadband satellite measurements. J. Climate, 2, 974985.

Chertock, B., R. Frouin, and R. C. J. Somerville, 1991: Global monitoring of net solar irradiance at the ocean surface: Climatological variability and the 1982-1983 El Niño. J. Climate, 4, 639-650.

Darnell, W. L., W. F. Staylor, S. K. Gupta, and F. M. Denn, 1988: Estimation of surface insolation using sun-synchronous satellite data. J. Climate, 1, 820-835.

Dedieu, G., P. Y. Deschamps, and Y. Kerr, 1987: Satellite estimation of solar irradiance at the surface of the Earth and of surface albedo using a physical model applied to METEOSAT data. $J$. Climate Appl. Meteor., 26, 79-87.

Dobson, F. W., and S. D. Smith, 1989: Bulk models of solar radiation at sea. Quart. J. Roy. Meteor. Soc., 114, 165-182.

Esbensen, S. K., and Y. Kushnir, 1981: The heat budget of the global oceans: An atlas based on surface marine observations. Climatic Res. Inst. Report No. 29, Oregon State University, Corvallis, Oregon, $220 \mathrm{pp}$.

Foot, J. S., 1988: Some observations of the optical properties of clouds. 1: Stratocumulus. Quart. J. Roy. Meteor. Soc., 114, 129-144.

Frouin, R., and B. Chertock, 1992: A technique for global monitoring of the net solar irradiance at the ocean surface. Part I: Model. J. Appl. Meteor., 31, 1056-1066.

- D. W. Lingner, C. Gautier, K. S. Baker, and R. C. Smith, 1989: A simple analytical formula to compute clear-sky total and photosynthetical available solar irradiance at the ocean surface. $J$. Geophys. Res., 94, 9731-9742.

Gautier, C., 1988: Surface Solar Irradiance in the central Pacific during tropic heat: Comparisons between in situ measurements and satellite estimates. J. Climate, 1, 600-608. and K. Katsaros, 1984: Insolation during STREX, Part 1: Comparison between surface measurements and satellite estimates. J. Geophys. Res., 89(D7), 11 779-11 788.

—, G. Diak, and S. Masse, 1980: A simple physical model to estimate incident solar radiation at the surface from GOES satellite data. J. Appl. Meteor., 19, 1005-1012.

McClatchey, R. A., R. W. Fenn, J. E. A. Selby, F. E. Voltz, and J. S. Garine, 1971: Optical properties of the atmosphere. AFCRLTR-71-0279, Envir. Res. Papers, No 354, L. G. Hanscom Field, Bedford, MA.

Möser, W., and E. Raschke, 1984: Incident solar radiation over Europe estimated from Meteosat data. J. Climate Appl. Meteor., 23, 166-170.

Pinker, R. T., and J. A. Ewing, 1985: Modeling surface solar radiation: Model formulation and validation. J. Climate Appl. Meteor., 24, 389-401.

Ramanathan, V., 1986: Scientific use of surface radiation budget data for climate studies. NASA Ref. Publ. 1169, J. T. Suttles and G. Ohrings, Eds., 132 pp.

Sellers, P. J., S. I. Rasool, and H.-J. Bolle, 1990: A review of satellite data algorithms for studies of the land surface. Bull. Amer. Meteor. Soc., 71, 1429-1447.

Sobolev, V., 1963: A Treatise on Radiative Transfer. Van Norstrand.

Stamnes, K., S. C.Tsay, W. Wiscombe, and K. Jayawiera, 1988: Numerically stable algorithm for discrete-ordinate-method radiative transfer in multiple scattering and emitting layer media. Appl. Optics, 27, 2502-2509.

Stephens, G. L., G. W. Paltridge, and C. M. R. Platt, 1978: Radiation profiles in extended water clouds. III: Observations. J. Atmos. Sci., 35, 2133-2141.

- S. Ackerman, and E. A. Smith, 1984: A shortwave parameterization revised to improve cloud absorption. J. Atmos. Sci., 41, 687-690.

Staylor, W. F., and A. C. Wilber, 1990: Global surface albedos estimates from ERBE data. Preprints, Seventh Conf. on Atmospheric Radiation. San Francisco, CA., Amer. Meteor. Soc., 231236.

Suttles, J. T., and G. Ohrings, 1986: Surface radiation budget for climate applications. NASA Ref. Publ. 1169, 132 pp.

Tarpley, J. D., 1979: Estimating incident solar radiation at the surface from geostationary satellite data. J. Appl. Meteor., 18, 11721181.

Tanré, D., C. Deroo, P. Duhaut, M. Herman, J.-J. Morcrette, J. Perbos, and P.-Y. Deschamps, 1990: Description of a computer code to simulate the satellite signal in the solar spectrum. Int. J. Remote Sens., 11, 659-668.

WCP-55, 1983: Report of the WMO Radiation Commission of IAMAP Meeting of Experts on Aerosols and their Climatic Effects, Geneva.

Welch, R. M., and B. A. Wielicki, 1989: Reflected fluxes for broken clouds over a Lambertian surface. J. Atmos. Sci., 46, 13841395.

Whitlock, C. H., W. F. Staylor, W. L. Darnell, M. D. Chou, G. Dedieu, P. Y. Deschamps, J. Ellis, C. Gautier, R. Frouin, R. T. Pinker, I. Laslo, W. B. Rossow, and T. Tarpley, 1990: Comparison of surface radiation budget satellite algorithms for downwelled shortwave irradiance with Wisconsin FIRE/SRB surface truth data. Preprints Seventh Conf. on Atmospheric Radiation, San Francisco, CA., Amer. Meteor. Soc., 237-242. 